\title{
Title: Xylem sap phosphorus sampling using microdialysis - a non-destructive high sampling frequency method tested under laboratory and field conditions
}

Authors: Jakub Jeřábek ${ }^{1 *}$, Michael Rinderer ${ }^{2}$, Arthur Gessler ${ }^{3,4}$, Markus Weiler $^{2}$

${ }^{1}$ Department of Landscape Water Conservation, Faculty of Civil Engineering, Czech Technical University in Prague, Prague, Czech Republic; ${ }^{2}$ Chair of Hydrology, Faculty of Environment and Natural Resources, University of Freiburg, Germany; ${ }^{3}$ Forest Dynamics, Swiss Federal Research Institute WSL, 8903 Birmensdorf, Switzerland ${ }^{4}$ Department of Environmental Systems Science, ETH Zurich, Zurich, Switzerland

${ }^{*}$ Corresponding author: Jakub Jeřábek (jakub.jerabek@,fsv.cvut.cz)

Keywords: microdialysis, xylem sap, phosphorus, diurnal nutrition variability, in situ measurement

This document is the accepted manuscript version of the following article: Jeřábek, J., Rinderer, M., Gessler, A., \& Weiler, M. (2020). Xylem sap phosphorus sampling using microdialysis - a non-destructive high sampling frequency method tested under laboratory and field conditions. Tree Physiology, 40(11), 1623-1638. https://doi .org/10.1093/treephys/tpaa081 


\section{Abstract}

2 For a better understanding of plant nutrition processes, it is important to study the flux of nutrients within plants. However, existing xylem sap sampling methods are typically destructive and do not allow for repeated, highly frequent measurements of nutrient concentration. In this paper, we present a novel use of microdialysis (MD) for characterizing xylem sap phosphate $\left(\mathrm{PO}_{4}{ }^{3-}\right)$ concentration as a possible alternative to destructive sampling. First, MD probes were tested under laboratory conditions in vitro, in a stirred solution test, and in vivo, using beech tree stem segments. Exponential decline in the relative recovery (RR) with an increasing MD pumping rate allows for determining an optimal sampling interval (i.e., the maximum amount of sample volume with the minimum required concentration). The RR changed only minimally, with a change in the simulated sap flow velocity during the in vivo stem segment test. This suggests that MD can be applied over a range of naturally occurring sap flow velocities. Differences in the ionic strength between the xylem sap and the perfusate pumped through the MD did not influence the RR. Then, MD was successfully applied in a $24 \mathrm{~h}$ field campaign in two beech trees of different ages and allowed for in situ assessments of the diurnal variation of $\mathrm{PO}_{4}{ }^{3-}$ concentration and (together with xylem flow measurements) flux variability in living trees. Both beech trees exhibited the same diurnal pattern in $\mathrm{PO}_{4}{ }^{3-}$ concentrations with higher concentrations in the younger tree. The xylem $\mathrm{PO}_{4}{ }^{3-}$ concentration measured with MD was in the same order of magnitude as that received through destructive sampling in the younger tree. The MD probes did not show a decline in RR after the field application. We showed that $\mathrm{MD}$ can be applied to capture the $\mathrm{PO}_{4}{ }^{3-}$ concentration dynamics in the

21 xylem sap with bihourly resolution under field conditions.

\section{Introduction}

Xylem sap sampling for chemical analysis is a problematic task due to large tension in the sap wood as reviewed e.g., by Schurr (1998). The sampling is usually done with destructive methods, such as the pressure chamber method (Netzer et al. 2017), the centrifugation method (Gourieroux et al. 
2016), vacuum pump extraction (Regulski et al. 1982) or gravitational displacement (Glavac et al. 1990). Beis et al. (2009) sampled sap from leaves with a leaf pressurization technique with several pressure steps applied. They found that the $\mathrm{pH}$ of the sap differs for the lowest pressure applied, and hence the chemical composition of the sample changed due to the sampling procedure. According to Schurr (1998), a common problem of destructive as well as non-destructive methods is that they cannot prevent mixing of sampled xylem sap with other compartments of the plant tissue even though techniques (e.g. ATP content measurements) are available to determine the cytoplasmic contamination of xylem sap (c.f. Schneider et al. 1996).

Microdialysis (MD) is a technique well established in neuroscience and pharmacokinetics in order to sample compounds from the intercellular space with minimal tissue damage and perturbation (Davies, 1999). MD uses a small probe ( $4 \mathrm{~cm}$ in length and $<1 \mathrm{~mm}$ in diameter in our case) with a membrane that allows for a diffusive exchange between the substances that surround the membrane (here, the xylem) and the perfusate, a liquid that is pumped through the MD probe. MD is therefore a non-destructive (or a minimal tissue-damage causing) but invasive method (for more details on MD see section 2).

Recently, MD has been used in environment-related research (Miró et al. 2005), for instance in soil sciences to estimate plant-available N (Inselsbacher et al. 2011), P root uptake (Demand et al. 2017), or to study amino acid dynamics with high temporal resolution (Warren 2018) and in plant sciences to measure metal ions in tomatoes (Torto et al. 2002), pesticide residues in jade plants (Zhou et al. 2008, 2009), or ascorbic-acid concentration and antioxidant capacity in Opuntia ficusindica (Pretti et al. 2014). To our knowledge, the application of MD in xylem wood of mature trees is novel and has not been carried out before.

The potential advantages of MD for xylem sap sampling are the following:

1) MD probes can be installed into the xylem of trees (i.e., plants with secondary growth) without causing substantial damage to the plant tissue and allows for subsequent sampling from a 
single location on the plant body. Even though single xylem vessels might be damaged, lateral water transport in the xylem (Bull et al. 1972) is presumed to allow effective probing.

2) The passive diffusion principle of dialysis does not require the actual sap to be extracted.

As the perfusate is slowly pumped through the membrane to yield a sample (e.g., $10 \mu \mathrm{L} \mathrm{min}{ }^{-1}$ ), the time for diffusive exchange through the MD membrane is limited, and only a fraction of the real concentration in the xylem wood is sampled. This fraction is called the relative recovery (RR). Among other factors, the RR largely depends on the pumping rate, which controls the flow of the perfusate through the probe (Stenken 1999) and is also affected by the transport properties of the material surrounding the probe (Bungay et al. 1990). The effect of the pumping rate and surrounding material transport properties on the RR needs to be characterized through calibration in order to derive concentration measurements with MD. In vitro (e.g., stirred solution test) and in vivo calibrations (e.g., stem segment tests) need to be undertaken separately to assess both the effect of the pumping rate and the surrounding material transport properties. The convection flux around the MD probe (e.g. revolutions per minute (RPM) of a magnetic stirrer), which is a function of the flow and transport properties in the surrounding material, may also affect the probe RR due to the changing concentration depletion zone around the probe (Stenken 1999, Zhou et al. 2008). In the case of xylem sap sampling, the convection flux of xylem sap around the probe membrane changes due to the daylight cycle and the meteorological conditions affecting the water pressure deficit between the leaf and atmosphere and the stomatal conductance. It is therefore necessary to perform an in vivo calibration to identify the effect of xylem sap flow velocity on the MD probe RR.

Although xylem sap $\mathrm{PO}_{4}{ }^{3-}$ concentration was measured in our study, $\mathrm{MD}$ is applicable to other chemical substances. $\mathrm{PO}_{4}{ }^{3-}$, in particular it is essential for plant metabolism (Lang et al. 2016), and there is evidence that phosphorus $(\mathrm{P})$ becomes a limiting factor in forest ecosystems (Goswami et al. 2018) due to the low rates of mineralization and its low mobility on the one hand and high anthropogenic nitrogen deposition in the northern hemisphere on the other, which may enhance the P demand of trees. (e.g., Jonard et al. 2015). The soil-plant-microbe interaction in respect of the 
ecosystem P relationship is far from being understood (Lang et al. 2016), and characterizing and quantifying the $\mathrm{P}$ uptake by plants is necessary to understand the $\mathrm{P}$ fluxes in the entire forest ecosystem.

As plant nutrition exhibits day and night variations, diurnal measurement of chemical compounds in plant tissues are of particular interest. Köstner et al. (1998) reported higher organic sulfur during the night compared with daylight in the xylem sap of the Norway spruce (Picea abies), whereas the diurnal changes of inorganic sulfur were insignificant. Xylem sap composition for major ions in well-controlled conditions was measured diurnally in poplars (Populus tremula x P. alba) by Siebrecht et al. (2003), and these authors showed that ion concentrations were highest in the late morning and lowest at dusk. Major ions translocation (concentration multiplied by sap flow) was lowest in the middle of the night (Siebrecht et al. 2003). In addition, root uptake of nutrients shows diurnal variations; e.g., the highest ammonium uptake was observed at noon in both beech and spruce trees (Gessler et al. 2002).

In addition, seasonal differences were observed in nutrient fluxes in plants. Within the course of a year the highest concentration of ions in the xylem sap was reported in March and April in 42-yearold beech trees in central Germany (Glavac et al. 2006). Similarly, the highest concentration of total $\mathrm{P}$ and inorganic $\mathrm{P}$ was observed in spring in the xylem sap of mature beech trees in the Conventwald site in Germany (Netzer et al. 2017). Towards early summer, the concentration of total and inorganic $\mathrm{P}$ decreased while the concentration of organic $\mathrm{P}$ remained constant (Netzer et al. 2017).

All of these studies used destructive sampling techniques for xylem sap sampling. The main objective of this paper is to propose $\mathrm{MD}$ as a non-destructive alternative for the analysis of $\mathrm{P}$ in xylem sap that allows for high (i.e., hourly) temporal resolution sampling. We systematically tested the effect of the MD perfusate pumping rate and xylem flow velocity in the lab and show the successful application of MD to measure diurnal variability in phosphate concentrations in mature beech trees in the field, something that has not been reported in the literature so far. 


\section{Material and methods}

104

105

106

107

108

109

110

111

112

113

114

115

116

\subsection{The principle of microdialysis}

Microdialysis (MD) is based on the dialysis principle where passive diffusion takes place between two liquids separated by a membrane (Stenken 1999). Figure 1 depicts the sketch of a MD probe. Through the inlet tubing the perfusate, a liquid with a known chemical composition, is pumped with a known rate (e.g., $10 \mu \mathrm{L} \mathrm{min}^{-1}$ ) to the top of the cylindrical membrane. In the medium surrounding the probe, the substance of interest is typically present in higher concentrations and thus diffuses through the membrane into the probe. Depending on the flux rate of the surrounding medium and the diffusion rate of the substance between the surrounding medium and the perfusate, a depletion zone is potentially established around the membrane. The enriched solution in the probe (dialysate) is collected with the outlet tubing. The ratio of sampled dialysate concentration $\left(C_{\text {dial }}\right)$ and the concentration of the substance in the surrounding medium, i.e., the analyte, $\left(C_{\infty}\right)$ is called the relative recovery (RR) and it is defined as

$$
R R=\frac{C_{\text {dial }}-C_{p e r}}{C_{\infty}-C_{p e r}}
$$

where $C_{p e r}$ stands for the concentration in the perfusate, which is controlled by the user.

The RR is dependent on the contact time between the perfusate and the surrounding solution. The contact time is controlled by the pumping rate $\left(Q_{\text {pump }}\right)$ of the perfusate. A typical parametric relationship between the RR and $Q_{\text {pump }}$ was derived by Stenken (1999) as

$$
R R=a-\exp \left(-k / Q_{\text {pump }}\right)
$$

where $a$ and $k$ stand for dimensionless parameters that are probe-type specific (parameter $a$ theoretically equals 1). The relationship (2) describes the $\mathrm{RR}$ as a function of $Q_{\text {pump}}$, which is the pumping rate of the perfusate. $C_{\infty}$ can be calculated with Eq. 1 if the calibration curve Eq. 2 and concentration $\mathrm{C}_{\text {dial }}$ and $\mathrm{C}_{p e r}$ are known. 
It is hypothesized that the RR also depends on the flux rate of the medium around the probe; i.e. the

xylem sap flow velocity in our case. Xylem sap flow velocity can affect the concentration depletion zone around the probe, and therefore the diffusion rate into the probe. We assessed whether and how the RR also depends on the xylem sap flow velocity $\left(J_{x y l e m}\right)$ through the convection effect and transport resistance of the xylem sap for diffusion. In that case, the RR also becomes a function of $J_{x y l e m}, \operatorname{RR}\left(Q_{\text {pump }}, J_{x y l e m}\right)$. This function was measured in the laboratory, and the concentration of the analyte $\left(C_{\infty}\right)$ was calculated as

$$
C_{\infty}=C_{p e r}+\frac{C_{\text {dial }}-C_{p e r}}{R R\left(Q_{\text {pump }}, J_{x y l e m}\right)}
$$

134 The distinct ionic strength of analyte and perfusate can also affect transport through the membrane 135 (Miró and Frenzel 2004, Zhou et al. 2008, Demand et al. 2017). The ionic strength effect was analyzed in this paper during the in vivo measurement. Temperature also affects the RR since diffusion is temperature-dependent (Inselsbacher and Näsholm 2012), according to the EinsteinStokes equation. The temperature effect, however, differs for chemical species with different molecular weight, as measured in the soil (Inselsbacher and Näsholm 2012). The temperature effect was not systematically tested in our study, since the complete chemical composition of the xylem 141 sap in a living tree was not analyzed. We thus could not directly transfer the temperature effect 142 obtained from the laboratory calibration to the field measurement. However, we discuss the potential effect of temperature and associated changes in the diffusion rate on MD measurements in general. It also was reported that $\mathrm{pH}$ has an effect on the RR (Sulyok et al. 2005); however, it was 145 found that this effect is insignificant between pH 3.5 and 6.5 (Demand et al. 2017) and thus was not 146 relevant for xylem probing (cf., Thomas and Eamus 2002).

147 In vitro stirred solution and in vivo stem segment calibration was undertaken in the laboratory 148 before the xylem sap measurement in living beech trees was conducted in the field. With the 149 calibration procedure we investigated the effect of the pumping rate $Q_{\text {pump }}$ and xylem sap flow velocity $J_{x y l e m}$ on the RR. Finally, a case study, utilizing MD was carried out in a beech forest field 
151 site in southwest Germany, where the xylem sap $\mathrm{PO}_{4}{ }^{3-}$ was sampled during a 24-hour measurement 152 campaign.

\subsection{Laboratory tests}

154

155

156

157

158

159

160

161

162

163

164

165

166

167

168

169

170

171

172

173

174

\section{Stirred solution test}

Calibration in the form of in vitro stirred solution tests was done in order to determine the parameters of the relationship between the RR and $Q_{\text {pump }}$ (Eq. 2). CMA 20 probes (CMA, 2018) with a PAES (Polyarylethersulfone) membrane with a $20 \mathrm{KDa}$ molecular cutoff were used in this study. Figure 2 depicts the setup of this measurement. The MD probe was placed into a stirred $\mathrm{PO}_{4}^{3-}$ solution (analyte) with a known chemical composition $C_{\infty}$. A standard solution of monosodium phosphate $\left(\mathrm{NaH}_{2} \mathrm{PO}_{4}\right)$ with a concentration $C_{\infty}=416.7 \mu \mathrm{M}$ was used as an analyte. The perfusate consisted of de-ionized water containing no $\mathrm{PO}_{4}{ }^{3-}\left(C_{p e r}=0 \mu \mathrm{M}\right)$. Potassium chloride with a concentration of $20 \mathrm{mM}$ was added to both the analyte and the perfusate to reduce the ionic strength effect. A peristaltic pump (MINIPULS, Gilson, Inc., USA) and PVC tubes with inner diameters of 0.76 and $1.02 \mathrm{~mm}$ were used to pump the perfusate through the MD probes. Pumping rates $Q_{\text {pump }}$ of $5,7.5,10,15$, and $20 \mu \mathrm{L} \cdot \mathrm{min}^{-1}$ were chosen for the calibration. The $Q_{\text {pump }}$ range was chosen in order to obtain adequate sample volume in a reasonable sampling time. All stirred solution tests were performed in an air-conditioned laboratory, with air temperature set to $21{ }^{\circ} \mathrm{C}$.

In total, 51 samples were obtained with two different MD probes during the measurement (8 to 15 samples for each $Q_{\text {pump}}$ ). In a single measurement 0.3 to $1.2 \mathrm{~mL}$ of dialysate was collected. The samples were analyzed using the molybdenum blue method (Murphy and Riley, 1962; Drummond and Maher, 1995) utilizing a Unicam AquaMate photometer (Spectronic Unicam) with 700nm wavelength and a $1 \mathrm{~cm}$ cuvette to detect phosphor-molybdate (DIN EN ISO 6878). The calibration curve (Eq. 2) was obtained with the nonlinear least square optimization in $\mathrm{R}$ software (R Core Team, 2019). 
175

176

177

\section{Stem segment test}

In vivo stem segment tests were performed in order to examine the effect of xylem sap flow velocity and material properties on the RR. All measurements were undertaken with stem segments of ca. 20-year-old beech trees (Fagus sylvatica). Figure 3 shows the setup of the procedure. Stem segments with lengths ranging from 30 to $100 \mathrm{~cm}$ and diameters from 7 to $8.5 \mathrm{~cm}$ were collected in a local forest and transported in a water barrel $(30 \mathrm{~cm}$ stem segments $)$ or with sealed ends $(100 \mathrm{~cm}$ stem segments) to the lab within two hours after collection and refrigerated. In the lab 5-10 $\mathrm{cm}$ of the segments were cut off on both sides of each stem segment before vertically fixing the stem segments with clamps. Both ends of the stem segment were equipped with tubing attached to the stem segment by a heat shrinking tube and sealed with silicone. Sap flow through the stem segment was simulated by introducing a pressure head by means of a water column on top of the upper end of the stem segment. The sap flow velocity was calculated from the weighed analyte dropping from the stem segment and stem segment cross-section area (all of the cross-section contributed to the sap flow during the step segment test). Each stem segment was flushed with the analyte, a $\mathrm{PO}_{4}{ }^{3-}$ solution $\left(\mathrm{NaH}_{2} \mathrm{PO}_{4}\right.$ and $\left.\mathrm{KCl}\right)$, for two hours (shorter stems) or overnight (longer stems) before measuring. Longer stem segments were necessary to simulate slow sap flow velocities. MD probes were inserted in a predrilled hole $1.7-2 \mathrm{~cm}$ deep (the MD chamber) with a drill bit of $1 \mathrm{~mm}$ in diameter. A $14 \mathrm{~mm}$ long metal tube was installed 7-9 $\mathrm{mm}$ into the chamber in order to fix the shaft of the probe during installation (see Figure 3). Probes were flushed with perfusate for 20 minutes before sample collection began. Sampling time was 1 to 1.5 hours to yield $0.6-0.9 \mathrm{ml}$ of sample. All in vivo calibration measurements were done with a pumping rate of $10 \mu \mathrm{L} \mathrm{min}^{-1}$. This flow velocity was chosen based on the in vitro results as an appropriate tradeoff between the sample volume and sampling time. A total of 83 samples were collected. Different combinations of $\mathrm{KCl}$ and $\mathrm{PO}_{4}^{3-}$ concentrations were used in the analyte and perfusate to consider a range of sap compositions and ionic strengths (see Table 1). The simulated analyte xylem sap flow velocity ranged from 0.4 to 28.1 $\mathrm{cm} \cdot \mathrm{h}^{-1}$ (range estimates based on Hentschel et al. 2013). The stem segments were replaced every 
first or second day to avoid influences by a potential decay of the wood or xylem embolism. All

samples were measured under room temperature conditions (approx. $21^{\circ} \mathrm{C}$ ).

\section{Effect of xylem flow rate}

The effect of xylem sap flow velocity $J_{x y l e m}$ on the RR was evaluated in order to relate MD measurements in a living tree to absolute $\mathrm{PO}_{4}{ }^{3-}$ concentrations and to find the calibration relationship between the RR and $J_{x y l e m}$. All 83 samples were used to derive the relationship. The effect of xylem sap flow velocity was assessed by linear regression and by t-test for zero slope and intercept of the linear relationship.

In order to assess the effect of varying stem segment properties, subsets of the data were statistically analyzed with ANOVA. The $J_{x y l e m}$ measured with 3 stem segments was classified in 2 levels with $J_{x y l e m}<=6.9 \mathrm{~cm} \mathrm{~h}^{-1}$ and $6.9<J_{x y l e m} \leq 10.04 \mathrm{~cm} \mathrm{~h}^{-1}$ (based on $1 / 3$ and $2 / 3$ quantile of $J_{x y l e m}$ data). Table 2 presents an overview of the data used. By this procedure a total number of 30 data points were obtained. This subset of the full dataset was selected in order to maximize the number of repetitions of tested stem segments and classified xylem sap flow velocity combinations (Table 2). As different stem segments may affect the RR, the interaction between $J_{x y l e m}$ and the stem segment used was also tested.

\section{Effect of ionic strength}

The RR is potentially affected by the ionic strength of the perfusate relative to the surrounding medium, as large differences can lead to an osmotic potential. A test was performed with two concentrations of analyte $\left(41.7\right.$ and $125 \mu \mathrm{M} \mathrm{NaH}{ }_{2} \mathrm{PO}_{4}$ with ionic strengths of 250.5 and $\left.750 \mu \mathrm{M}\right)$ and perfusate (20 and $500 \mathrm{mM} \mathrm{KCl}$ with ionic strength of the same values). Those four concentration combinations were tested with three replications. A total of 12 data samples were collected. Three MD probes and two stem segments (one for each analyte concentration) were used. The final results were analyzed with ANOVA to test which variable (analyte or perfusate concentration) causes changes in the RR or as a consequence whether ionic strength affects the RR 
of $\mathrm{PO}_{4}{ }^{3-}$ in xylem sap. Differences in the stem segment properties lead to a variability of $J_{x y l e m}$ between 6.8 and $11.2 \mathrm{~cm} \mathrm{~h}^{-1}$.

\subsection{Field application}

To explore MD probe performance under natural conditions, a $24 \mathrm{~h}$ measurement campaign for assessing $\mathrm{PO}_{4}{ }^{3-}$ concentrations in the xylem sap was performed between 2 May and 3 May 2018 at the Conventwald experimental site in the Black Forest, Baden-Württemberg, Germany. The beginning of May was chosen, based on the long-term phenological data provided by the Climate Data Center (Deutscher Wetterdienst 2018), as it is the beginning of the vegetation season where high nutrition concentrations in xylem may be expected.

\section{Site Description}

The Conventwald experimental site $(\mathrm{CON})$ is located in the Black Forest, ca. $15 \mathrm{~km}$ east of Freiburg, Baden-Württemberg, Germany (4801'16"N 757'56"E). The site altitude is 766 m a.s.1.; the climatic zone is temperate oceanic. The mean annual precipitation is $1749 \mathrm{~mm}$ with a mean annual temperature of $6.8{ }^{\circ} \mathrm{C}$. The geological parent material is Paragneiss with a soil-saprolite depth between 280 and $300 \mathrm{~cm}$. The soil type is loam in the topsoil and sandy loam in the subsoil (WRB 2015). The soil exhibits a large portion of gravel fraction. Total P stock per unit area is 7.5 mol m $\mathrm{m}^{-2}$ up to $1 \mathrm{~m}$ soil depth (Lang et al. 2017). Total $\mathrm{P}$ concentration in the A horizon is $30 \mathrm{mmol}$ $\mathrm{kg}^{-1}$ from which $0.77 \mathrm{mmol} \mathrm{kg}^{-1}$ is bioavailable (Lang et al. 2017). The site is covered with mixed forest dominated by beech (Fagus sylvatica, 69\%) and silver fir (Abies alba, 31\%). The tree age is about 130 years. The mean height is $27.6 \mathrm{~m}$ and mean breast height diameter is $40 \mathrm{~cm}$. There were 312 beech trees per hectare determined at the CON site (Lang et al. 2017).

\section{Sampling setup}

248 The measurements were undertaken in two beech trees with different ages (10 and ca. 130 years).

249 Three probes were installed in each tree as shown in Figure 4 (see details below). All probes were 250 installed one day prior to the experiment and flushed with perfusate for four hours prior to the 
experiment. Two peristaltic pumps, Gilson Minipuls ${ }^{\circledR}$ 3, were used to push the perfusate through 252 the probes. A potassium chloride solution $(\mathrm{KCl})$ with a concentration of $20 \mathrm{mM}$ was used as perfusate. The dialysate samples were collected into plastic vials and stored in a cooling box before bringing them all to the lab for analysis. The $\mathrm{PO}_{4}{ }^{3-}$ concentrations were determined within six hours after the end of the $24 \mathrm{~h}$ measurement. An in vitro stirred solution test of the MD probes was performed in the lab prior to and after the field test to assess the effect of a change in membrane properties due to the installation in living wood.

The $24 \mathrm{~h}$ measurement started at 15:50 on 2 May 2018 and a sample was taken from each probe every $2 \mathrm{~h}$. In total the $6 \mathrm{MD}$ probes yielded 72 samples. The perfusate was pumped with a pumping rate of $10.07 \pm 0.39 \mu \mathrm{L} \mathrm{min}{ }^{-1}$. In addition, xylem sap flow velocities were measured in each tree using EAST30 heat pulse sensors (EAST 30 Sensors, Washington) (orientation of the heat pulse sap flow sensor in both trees is shown in Figure 4). Stem temperature data were extracted from the raw heat pulse sensors' sensor data (the initial temperature of the lower needle of the heat pulse sensors), and air temperature was measured by a logger temperature sensor located in the vicinity of both trees.

\section{MD-Probe installation procedure in the field}

267 The probes needed to be inserted into the rigid xylem tissue, where contact between the membrane 268 and xylem sap had to be preserved. As it was noted during preliminary testing, the installation 269 procedure is crucial for adequate contact between the probe membrane and the xylem sap, and thus 270 for the probe's functionality. The following steps of the installation were optimized after 271 experiencing several failures in the field the previous season:

272 1) $1 \mathrm{~cm}^{2}$ of bark and phloem was removed from the mature beech tree before the probes were 273 installed.

274 2) A $0.5-0.7 \mathrm{~cm}$ deep hole was drilled in the xylem wood with a drill bit of $1.2 \mathrm{~mm}$ in diameter.

275 3) The MD chamber was extended to $2.5 \mathrm{~cm}$ with a drill bit of $1 \mathrm{~mm}$ in diameter. 
4) a $14 \mathrm{~mm}$ long iron shaft was inserted to a depth of $0.5-0.7 \mathrm{~cm}$ into the prepared MD chamber in order to fix the probe during installation.

5) The MD chamber was flushed and filled with deionized water using a syringe within seconds after the drilling (Figure 5A).

280 6) The MD probe was carefully inserted into the MD chamber immediately after the chamber 281 was filled with the deionized water (Figure 5BC).

282 7) The iron shaft with the MD probe was sealed with silicone (Figure 5D).

283 A fully installed silicone sealer probe is shown in Figure 5E.

284 Probes were installed the day before the experiment and flushed with perfusate for four hours 285 directly after installation and again prior to the experiment. Flushing was done in order to remove 286 possible air bubbles from the tubing system.

287 Probes were carefully removed from the MD chamber after the experiment. The diameter of the $288 \mathrm{MD}$, chamber, which was slightly larger than the membrane diameter, allowed for removal of the 289 MD probes from the MD chamber without damage. A knife was used to remove the silicon from the bark of the tree; thus, the silicon stayed glued to the "head" of the MD probe.

\section{Destructive xylem sap sample as control}

292 The younger beech tree was cut off after the measurement to collect samples from its sap as a 293 reference to evaluate the measured $\mathrm{PO}_{4}{ }^{3-}$ concentrations with the new approach presented in this paper. Tree stem segments of length of ca $50 \mathrm{~cm}$ were collected from a height of $20-70 \mathrm{~cm}, 70-120$ $\mathrm{cm}$, and from 120-170 $\mathrm{cm}$ above the ground. Stem segments were sealed with plastic sheets on both sides and immediately transported to the lab.

The xylem sap was extracted and measured directly after the end of the $24 \mathrm{~h}$ measurement with a gravitational displacement method by applying a hydraulic potential (water column) to the top of the stem segment and collecting the displaced water at the bottom. We followed the procedure 
301 from both ends of the stem segment $(\mathrm{ca} .10 \mathrm{~cm}$ ) and a sealed shrinking tube was put at the upper

302 end of the stem segment where the water column pressure was applied. Parts that had been stripped 303 of the bark-end phloem were tightly wrapped in paper towels in order to prevent and/or reveal 304 potential contamination by leaking water (which did not occur). Since the initial fractions of the 305 displaced xylem sap might have been contaminated with constituents of destroyed cells, the first 2$3065 \mathrm{ml}$ were discarded. Thereafter, two consecutive samples with a volume of $2-5 \mathrm{ml}$ were collected 307 and directly analyzed with the molybdenum blue method (see section 2.2 above). Weber et al. 308 (1998) showed with berberine chloride as a tracer that sample dilution by the displacement solution 309 is low for the first portions of the xylem sap, as sampled in our study. Moreover, they excluded 310 significant contamination with cellular constituents by determining the ATP content of the xylem 311 sap.

\section{MD probes durability under field conditions}

313 To assess the potential decay of the $M D$ probe as a result of being used in a living tree, an in vitro 314 membrane test in stirred solution with known $\mathrm{PO}_{4}{ }^{3-}$ concentration was performed before and after 315 the field campaign. The test undertaken before the experiment also served as a control for the 316 correct functionality of the probe and membrane, and to reveal possible leakage of the tubing. The 317 same test was performed after the experiment to show potential decay effect of the probes and to 318 check for a possible decrease in relative recovery.

\section{Results}

\subsection{Laboratory tests: Effect of the pumping rate on the relative recovery}

321 The $\mathrm{PO}_{4}^{3-} \mathrm{RR}$ decreased exponentially with the increasing pumping rate (see Figure 6). The 322 obtained parameters for Eq. 2 are: $a=1.017[-]$ and $k=1.265[-]$ and the exponential function 323 explains $95 \%$ of the data variability. The RR values were between $7.5 \%$ to $25 \%$ for pumping rates 324 between 5 to $20 \mu \mathrm{L} \mathrm{min}^{-1}$, which corresponds to the values reported in the literature (Stenken 1999, 
Demand et al. 2017). The variability of RR within the samples of each pumping rate was smallest for the $5 \mu \mathrm{L} \mathrm{min}^{-1}$ pumping rate (Interquartile Range $(\mathrm{IQR})=1.38 \%$ ) and highest for the $20 \mu \mathrm{L} \mathrm{min}{ }^{-}$ ${ }^{1}$ pumping rate $(\mathrm{IQR}=2.46 \%)$

\subsection{Laboratory tests: Effect of xylem sap flow velocity $\left(U_{x y l e m}\right)$ on the RR}

The effect of xylem flow velocity $J_{x y l e m}$ on the RR is shown in the Figure 7. A linear relationship was fitted through the data to obtain a calibration curve, which was used to interpret the diurnal measurement data in the field shown below. The data points exhibit large variability, and therefore the linear regression yields a low $\mathrm{R}^{2}$ value $\left(\mathrm{R}^{2}=0.17\right)$. The slope of the linear function fitted to the data is 0.179 and thus small. This means that the RR only slightly increases with xylem sap flow velocity. The hypothesis of zero slope and intercept of the linear expression (shown in Figure 7) was tested using the student t-test (in Table 3). The null hypothesis was rejected in both cases with a 336 level of significance $\alpha=0.05$.

337 The effect of both the varying stem segment transport properties and $J_{x y l e m}$ was tested with ANOVA 338 (Table 4). The results indicated no significant effect of the used stem segment and $J_{x y l e m}$ on the RR. 339 No significant interaction between those effects was observed (Table 4). Only the intercept effect 340 was significant (Table 4). Results of this test indicated that different stem segments and potential 341 differences in transport properties do not override the effect of the $J_{x y l e m}$.

\section{Effect of ionic strength on the RR}

343 In order to assess the effect of varying $\mathrm{PO}_{4}{ }^{3-}$ concentration in the analyte and $\mathrm{KCl}$ concentration in

344 the perfusate during the stem segment measurements, an ANOVA was performed. Mean RR and 345 standard deviation (in brackets) with three replications are displayed in Table 5. Higher 346 concentration of $\mathrm{KCl}$ in perfusate increased the $\mathrm{RR}$. Higher $\mathrm{PO}_{4}{ }^{3-}$ analyte concentration increased 347 the mean RR and RR standard deviation. 
Results of ANOVA for varying $\mathrm{PO}_{4}{ }^{3-}$ and $\mathrm{KCl}$ concentration are shown in Table 6 . Only $29 \%$ of the

variability of the $\mathrm{RR}$ is explained by $\mathrm{PO}_{4}{ }^{3-}$ and $\mathrm{KCl}$ concentration, and both effects are not

significant. Only the intercept (Table 6), which represents a constant offset, was significant. It was

therefore concluded that all other factors did not significantly affect the RR.

\subsection{Field testing: diurnal measurement}

Xylem $\mathrm{PO}_{4}{ }^{3-}$ concentrations calculated from $C_{\text {dial }}$ using Eq. 3 was higher for the young compared to the mature beech tree but both trees showed the same diurnal pattern of $C_{\text {dial }}$ and $\mathrm{PO}_{4}{ }^{3-}$ variability (Figure 8). $\mathrm{PO}_{4}{ }^{3-}$ concentrations decreased during the late afternoon on day 1 along with a decrease in sap flow velocities from $2 \mathrm{~cm} \mathrm{~h}^{-1}$ to almost zero $\mathrm{cm} \mathrm{h}^{-1}$. During the night $\mathrm{PO}_{4}{ }^{3-}$ concentrations increased and reached a peak of $456 \mu \mathrm{M}$ and $292 \mu \mathrm{M} \mathrm{PO} 4^{3-}$ in the young and mature tree, respectively, at the end of the night. After sunrise, $\mathrm{PO}_{4}{ }^{3-}$ concentrations started to decrease again down to $121 \mu \mathrm{M}$ and $51 \mu \mathrm{M}$ in the young and mature beech tree, respectively. When the sky cleared up at midday $\mathrm{PO}_{4}{ }^{3-}$ concentrations in both trees experienced a second peak of $475 \mu \mathrm{M}$ and $162 \mu \mathrm{M}$ $\mathrm{PO}_{4}{ }^{3-}$ concentrations (young and the mature tree, respectively) followed by a decline during the late afternoon, similar to the pattern observed on day 1 .

$363 \mathrm{PO}_{4}{ }^{3-}$ mass fluxes were dominated by the change in sap flow velocities between day and night 364 (Figure 8). $\mathrm{PO}_{4}{ }^{3-}$ mass fluxes were generally low during night and did not show a peak towards the 365 end of the night as observed in $C_{\text {dial }}$ and $\mathrm{PO}_{4}{ }^{3-}$ concentrations (see above). Night $\mathrm{PO}_{4}{ }^{3-}$ mass fluxes

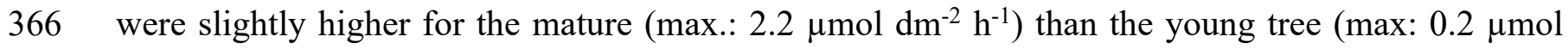
$367 \mathrm{dm}^{-2} \mathrm{~h}^{-1}$ ) due to differences in sap flow velocities between both trees. During day when the sky was 368 clear $\mathrm{PO}_{4}{ }^{3-}$ mass fluxes increased with increasing sap flow velocities in both trees (max.: 15.8 $369 \mu$ mol.dm ${ }^{-2} \cdot \mathrm{h}^{-1}$ young and $4.1 \mu \mathrm{mol} \mathrm{dm}{ }^{-2} \mathrm{~h}^{-1}$ mature beech tree) on day 1 and (max.: $7.4 \mu \mathrm{mol} \mathrm{dm} \mathrm{dm}^{-2}$ $370 \quad{ }^{1}$ and $5.9 \mu \mathrm{mol} \mathrm{dm} \mathrm{d}^{-2} \mathrm{~h}^{-1}$ ) on day 2.

371 The temperature in the xylem fluctuated between 8.5 and $11{ }^{\circ} \mathrm{C}$ in the mature and between 7.5 and $11.5^{\circ} \mathrm{C}$ in the young beech tree with minimum temperature at 8 a.m. and maximal temperature in 
the afternoon of day 1 and 2 (Figure 9). Air temperature exhibit similar temperature pattern as the

374 one measured in the young beech tree.

375

\section{Destructive xylem sap sample}

For comparison with the in situ MD measurements, a destructive sample of xylem sap from the young beech tree was collected by gravitational displacement at the end of the field campaign. The $\mathrm{PO}_{4}{ }^{3-}$ concentrations were $115 \pm 45.7 \mu \mathrm{M}, 100 \pm 3.14 \mu \mathrm{M}$ and $73.6 \pm 4.9 \mu \mathrm{M}$ for the stem segments taken in 20-70 cm, 70-120 and 120-163 cm height above surface, respectively. The $\mathrm{PO}_{4}^{3-}$ concentration in the lower segment (where the MD probe was installed) was only slightly lower than the $\mathrm{PO}_{4}{ }^{3-}$ concentration of the last in situ MD measurement of the field campaign for the young tree which was $146.5 \pm 40.4 \mu \mathrm{M}$.

\section{MD probes durability under field conditions}

The MD probes were tested prior and after the $24 \mathrm{~h}$ measurement campaign using the stirred solution test described in the method section. In Figure 10 values of RR before and after the field campaign for all used probes are shown. Probes 1 to 3 were installed in the young beech tree, probes 4 to 6 in the mature beech tree. The field measurements did not substantially affect the RR of the probes. The within probe variability was higher than the prior/after single probe variability. The within probe variability was in the same order of magnitude than the variability observed during the in vitro measurement.

\section{Discussion}

\section{Variables affecting relative recovery}

In vitro laboratory stirred solution tests showed that the MD probes exhibited an exponential decay of the RR with increasing $Q_{\text {pump }}$; something that was also reported in other studies using MD probes in stirred solution tests (Stenken 1999, Miró et al. 2005, Demand et al. 2017). For practical 
applications the presented relationship between the RR and $Q_{\text {pump }}$ allows for an optimization of the

sampling interval. However, the minimum sampling interval is determined by the RR, and thus it is the $Q_{\text {pump }}$ that guarantees the required amount of sample with the minimum concentration necessary to perform the chemical analysis (i.e., $\mathrm{PO}_{4}{ }^{3-}$ ). All in vivo measurements with stem segments in the

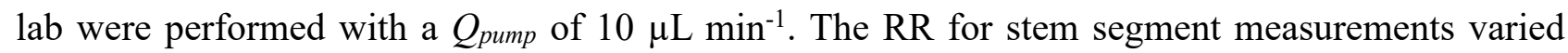
between $2.5 \%$ and $7.5 \%$ while the RR from the in vitro stirred solution tests using the same $Q_{\text {pump }}$ rate ranged between $10 \%$ and $15 \%$. The pumping rate could be reduced in order to obtain a higher RR. However, pumping rate reduction would lead to a coarser temporal resolution. In general, the RR from the stirred solution and stem segment were relatively low but realistic when compared to the RR in other studies that used a slower $Q_{\text {pump }}$. Demand et al. (2017), for instance, used a $Q_{\text {pump }}$ of $4 \mu \mathrm{L} \mathrm{min} \min ^{-1}$ and reported a RR of $14 \%$ in a laboratory stirred solution test. We might conclude that the discrepancy between the in vivo and in vitro measured RR in our study was caused by the resistivity of the surrounding material which increases the concentration depletion zone around the probes, this leading to lower recovery for the given $Q_{\text {pump }}$. Significant effects of the outer medium transport properties on the RR were also reported in the literature (Bungay et al. 1990).

The in vivo laboratory measurement exhibited a weak linear relationship between the RR and $J_{x y l e m}$ $\left(\mathrm{R}^{2}=0.17, \mathrm{p}\right.$-value for slope $\left.<0.01\right)$ associated with a large variability in $\mathrm{RR}$ (standard deviation $=$ $2.89 \%$ with mean $\mathrm{RR}=4.09 \%$ ). The slope of that relationship between the RR and $J_{x y l e m}$ was small (i.e., 0.179), suggesting that the RR varies only to a minor extent with changing $J_{x y l e m}$. The variability of $\mathrm{RR} \sim J_{x y l e m}$ relationship was further investigated by adding a different used stem segment in the model next to the classified $J_{x y l e m}$ (several stem segments were used during testing). In this case neither classified $J_{x y l e m}$ nor used stem segment showed significant effects in RR. This 418 has important implications for practical applications of MD in living trees, which naturally 419 experience changes in diurnal and seasonal sap flow velocities (e.g., Granier 1987, Zeppel et al. 420 2004). It was also shown that varying stem segment properties (here expressed by different stems used) do not influence the relationship between the $J_{x y l e m}$ and RR, indicating that the method can be 
XYLEM SAP PHOSPHORUS SMPLING USING MICRODIALYSIS

applied in different trees of the same species and still yield reliable results. Our work also showed that potential differences in ionic strength between the solution pumped through the MD probe and the matrix surrounding the probe, which is not known before MD probe installation or during measurements, has also no significant effect on the RR. Warren (2018) also failed to find any ionic strength difference effect for stirred solution measurement, with artificial soil solution, water and several organic nitrogen compounds used. Our results suggest that MD can be applied over a range of realistic xylem flow velocities and potential differences in ionic strength found in living trees (Zeppel et al. 2004, Lopushinsky 1986) without strong effects on the RR.

\section{Xylem sap sampling in the field}

The MD probe installation procedure turned out to be crucial for successful $\mathrm{PO}_{4}{ }^{3-}$ sampling in living trees. We therefore suggest following the detailed protocol given in the method section. It is advisable to avoid periods of summer dryness, where the xylem water potential in trees can be very low (<-10 MPa (e.g., Martínez-Vilalta and Garcia-Forner 2017) and the risk is high that the MD probe has no contact with the sap. During the measuring campaign in May with moderate moisture deficits and air temperature, however, it was possible to successfully install all probes. Earlier attempts with a simpler procedure and under dry summer conditions were not successful in enabling proper functioning of the MD sampling.

We need to assume that, even though our method is minimally invasive, placing the MD probes into the xylem might cause damage to living cells in the parenchymatic tissue of the stem and might also cause wound reactions. In the European beech parenchymatic cells make up between ca. $16 \%$ and $32 \%$ of the woody stem tissue (Morris et al. 2016). As a consequence, cellular constituents of destroyed cells might contaminate the xylem sap and thus lead to incorrect estimates of the xylem $\mathrm{PO}_{4}{ }^{3-}$ concentration. However, the other xylem sap sampling methods, which are even more destructive, also share the same problem. Schneider et al. (1996) tested the contamination with 
twigs of beech, where the xylem sap was sampled with the help of a pressure chamber. ATP is

assumed not to occur in the apoplastic space of the xylem and is thus a contamination marker. After

discarding the first portion of the xylem sap they determined cytoplasmatic contamination to be as

probes could lead to an initial increase in $\mathrm{PO}_{4}{ }^{3-}$ concentration in the perfusate. Later, however, the concentrations should decrease again due to dilution with the ascending xylem sap. Given that an initial $\mathrm{PO}_{4}^{3-}$ concentration peak was not seen in the field, and assuming that cytoplasmatic contamination upon insertion is comparable or even lower with our minimally invasive technique, we consider our results to be robust with respect to contamination. To get more quantitative insights into the degree of cytoplasmatic contamination, we suggest flushing stem segments with a solution without $\mathrm{PO}_{4}{ }^{3-}$ and determining the $\mathrm{PO}_{4}{ }^{3-}$ concentration in the perfusate.

\section{Diurnal variability in $\mathrm{PO}_{4}{ }^{3-}$ in living trees}

459 For the first time to our knowledge we show high-frequent in situ measurements of $\mathrm{PO}_{4}^{3-}$ 460 concentrations of xylem sap of living trees using MD probes. Independent of the tree's age, two 461 concentration peaks were observed during a $24 \mathrm{~h}$ measuring campaign. One peak occurred in the 462 night between 04:00 and 06:00, a second one between 12:00 and 14:00. In general, the measured $463 \mathrm{PO}_{4}{ }^{3-}$ concentrations were in a comparable range as shown by Siebrecht et al. (2003) for poplar 464 xylem but almost one order of magnitude lower than in kiwifruit vines (Clark et al. 1986). Herdel et al. (2001) showed, however, for the castor bean that even with a constant nutrient supply, phosphate concentrations in the xylem can vary between $0.1 \mathrm{mM}$ and $3 \mathrm{mM}$ and thus within one order of 467 magnitude within a few weeks.

468 Bimodal concentration patterns in the xylem with one peak at daytime and one at nighttime as 469 observed for $\mathrm{PO}_{4}{ }^{3-}$ in our study have been reported for $\mathrm{NO}_{3}{ }^{-}$in poplar (Siebrecht et al. 2003) and 470 castor bean xylem (Peuke et al. 2001). Siebrecht et al. (2003) also determined diurnal dihydrogen 471 phosphate concentrations, but a bimodal day-night pattern was not clearly expressed. The first peak 
in our study occurred at very low sap flow velocity (at night) and we might speculate that phosphate release from living cells in the xylem parenchyma might have contributed to that peak, since dilution with the ascending xylem sap would be low.

From the afternoon to the end of the night $\mathrm{PO}_{4}{ }^{3-}$ concentrations increased with decreasing xylem flow velocity. After sunrise, the onset of xylem flow coincides with a decrease in concentration.

477 These patterns point to a dilution of the $\mathrm{PO}_{4}{ }^{3-}$ pool by root water uptake and subsequent water transport in the xylem indicating that $\mathrm{P}$ uptake into and transport in the plant is not proportional to the water flux. Nutrient uptake is assumed to be an active and regulated process for which specific transport proteins are responsible (e.g., Santi et al. 2003). For phosphate, however, changes in the capacity of the P-uptake system in the roots are often assumed to have only small effects on the overall uptake (see e.g., Lambers et al. 2006) as the ability of the roots to mobilize sorbed phosphate, involving the release of carboxylates (e.g. Lambers et al. 2018) is the key limiting factor for uptake. We might assume that with a higher water flux in the soil-plant-atmosphere continuum 485 (as indicated by the higher xylem flow velocity), mobilization of $\mathrm{PO}_{4}{ }^{3-}$ might become limited, and 486 thus the concentration of $\mathrm{PO}_{4}{ }^{3-}$ decreases. The peak after midday seems to contradict this 487 assumption, but it has been shown that organic acid (citrate) exudation from roots that allows 488 phosphate mobilization shows diurnal oscillations with a midday peak (Watt and Evans 1999). This 489 is consistent with the finding that organic acids acting as iron-chelating phytosiderophores are also 490 preferentially released for several hours during the light period (Takagi et al. 1984). The increase in $491 \mathrm{PO}_{4}{ }^{3-}$ concentration after midday could thus be explained by a higher mobilization in the soil that 492 allows more intensive transport to, into and within the plant. Considering the higher sap flow 493 velocities during the light-period, the total flux of $\mathrm{PO}_{4}{ }^{3-}$ was largest during the daytime and smallest 494 at night. This dependency of nutrient fluxes in the xylem is also in agreement with other 495 observations on phosphate (Siebrecht et al. 2003) and also matches the findings of higher nutrient 496 uptake by the roots during periods of higher diurnal transpiration (Gessler et al. 2002). 
As mentioned above, temperature can also change the diffusion rate into the MD probe

498 (Inselsbacher and Näsholm 2012). The RR is therefore higher at higher temperatures and vice versa.

499 As the laboratory calibration was done under higher temperature conditions compared with the field 500 measurement, the actual RR under field conditions might have been lower and as a consequence the $501 \mathrm{PO}_{4}{ }^{3-}$ concentrations might have been higher than presented. As the temperature in the field 502 changed over the course of a campaign, this might have also affected the diurnal courses of RR. 503 However, in our case the temperature differences during the field campaign was in the order of 2 to $5045{ }^{\circ} \mathrm{C}$, and the $\mathrm{PO}_{4}{ }^{3-}$ concentrations determined from destructive sampling and from the in situ MD 505 measurements at the end of the experiment were similar. Small differences in $\mathrm{PO}_{4}{ }^{3-}$ concentration 506 between the two methods may be caused by the different sampling period (the gravitational 507 displacement was done a few hours after the last MD measurement), or by different spatial 508 integration of the measurements. While the MD probes determine the concentration in a small area 509 of the trunk, the displacement method integrates the whole sapwood. Still, since the destructive 510 sampling and MD-measurements yielded very similar $\mathrm{PO}_{4}{ }^{3-}$ concentrations we expect that the 511 difference in temperature between lab and field and between night and day in our study had a 512 limited influence on the $\mathrm{PO}_{4}^{3-}$ concentrations derived.

\section{Conclusions}

514 This paper presents a laboratory testing and field application of microdialysis (MD) for non515 destructive in situ xylem sap sampling for subsequent $\mathrm{PO}_{4}{ }^{3-}$ analysis in beech trees. Laboratory in 516 vitro stirred solution tests and in vivo stem segment tests were performed in order to assess the MD 517 probe's performance and to identify potential influencing factors when using MD in xylem wood. 518 MD probes were further tested in a $24 \mathrm{~h}$ measuring campaign under field conditions in a young (10 519 years) and a mature (130 years) beech tree.

520 Our results show that $\mathrm{MD}$ is a technique that is suitable to probe the xylem of trees for $\mathrm{PO}_{4}^{3-}$ 521 concentration assessments with the potential to also be applied to other nutrients. MD has the 
advantage to be minimally invasive and to provide concentration information with high temporal

resolution so that diurnal patterns can be assessed. The laboratory testing allowed for an investigation of the relationship between simulated xylem flow rate $\left(J_{x y l e m}\right)$, perfusate pumping rate $\left(Q_{\text {pump }}\right)$ and relative recovery $(\mathrm{RR})$ and ruled out potential interactions with tree specific xylem properties, and potential differences in ionic strength of the perfusate and the xylem sap. MD application in a field campaign exemplified the reliability of the method under natural conditions in living trees. Initial failures to measure $\mathrm{PO}_{4}{ }^{3-}$ in situ with $\mathrm{MD}$ showed that the installation procedure of the MD probes is crucial. For this reason, we have included a detailed description of our approach.

MD opens new avenues to understand the variability of nutrient transport in trees at the sub-daily but also at the seasonal time scale. If combined with other techniques, such as systems that allow to detect the depths of root water uptake by analyzing water isotopologues (Volkmann et al. 2016), MD has the potential to give insight into nutrient source depth and nutrient transport dynamics in living trees. The MD probes used in this study were originally designed for use in soft tissue and therefore are delicate. One possible future enhancement could therefore be to design more robust MD probes.

\section{Conflict of interest}

None declared.

\section{Funding}

541 This project was carried out within the framework of the priority program SPP 1685 "Ecosystem

542 Nutrition: Forest Strategies for limited Phosphorus Resources," funded by the German Research 543 Foundation DFG (grant No. WE 4598/7-2). JJ was supported by the German Federal Environmental 544 Foundation (Deutsche Bundesstiftung Umwelt - DBU) and by the internal CTU in Prague student grant SGS18/122/OHK1/2T/11. MR was supported by the DFG grant mentioned above. 
547 We would like to thank Karl Merz (Forstbotanical Garden University of Freiburg) and Barbara 548 Herbstritt (head of the hydrochemical laboratory of the Chair of hydrology of the University of 549 Freiburg) and Delon Wagner and Fabian Jeworowsky (precision mechanics) for collaboration and 550 support during the project. We also would like to thank independent reviewers for improving the 551 manuscript.

\section{Authors' Contributions}

$553 \mathrm{JJ}, \mathrm{MR}, \mathrm{AG}, \mathrm{MW}$ developed the experimental design, and JJ tested the method in the lab, conducted 554 the field measurements and laboratory analysis. JJ processed the data and performed the statistical 555 analysis including graphs and tables. JJ and MR wrote the manuscript; AG provided the plant 556 physiological interpretation of results. JJ and MR incorporated review comments of AG, MW and 557 external reviewers. 


\section{References}

560 Beis A, Zotos A, Patakas A (2009) Influence of sampling time and sap extraction methodology on 561 xylem $\mathrm{pH}$ values in two grapevine varieties grown under drought conditions. Environ Exp Bot $562 \quad 67: 305-311$.

563 Bull TA, Gayler KR, Glasziou KT (1972) Lateral Movement of Water and Sugar Across Xylem in 564 Sugarcane Stalks. Plant Physiol 49:1007-1011.

565 Bungay PM, Morrison PF, Dedrick RL (1990) Steady-state theory for quantitative microdialysis of 566 solutes and water in vivo and in vitro. Life Sci 46:105-119.

567 CLARK CJ, HOLLAND PT, SMITH GS (1986) Chemical Composition of Bleeding Xylem Sap 568 from Kiwifruit Vines. Ann Bot 58:353-362.

569 Davies MI (1999) A review of microdialysis sampling for pharmacokinetic applications. Anal Chim $570 \quad$ Acta 379:227-249.

571 Demand D, Schack-Kirchner H, Lang F (2017) Assessment of diffusive phosphate supply in soils 572 by microdialysis. Zeitschrift fur Pflanzenernahrung und Bodenkd 180:220-230.

573 Deutscher Wetterdienst (2018) German Meteorological Service. Offenbach am Main, Germany. 574 https://www.dwd.de

575 DIN (2004) DIN ES ISO 6878 - Water quality determination for phosphorus - Ammonium 576 molybdata spectrometric method.

577 Drummond L, Maher W (1995) Determination of phosphorus in aqueous solution via formation of 578 the phosphoantimonylmolybdenum blue complex. Re-examination of optimum conditions for the 579 analysis of phosphate. Anal Chim Acta 302:69-74. 
Gessler A, Kreuzwieser J, Dopatka T, Rennenberg H (2002) Diurnal courses of ammonium net

581 uptake by the roots of adult beech (Fagus sylvatica) and spruce (Picea abies) trees. Plant Soil 240:23-32.

GLAVAC V, KOENIES H, EBBEN U (1990) Seasonal variations in mineral concentrations in the

trunk xylem sap of beech (Fagus sylvatica L.) in a 42-year-old beech forest stand. New Phytol 116:47-54.

Goswami S, Fisk MC, Vadeboncoeur MA, Garrison-Johnston M, Yanai RD, Fahey TJ (2018)

Phosphorus limitation of aboveground production in northern hardwood forests. Ecology 99:438449.

Gourieroux AM, Holzapfel BP, Scollary GR, McCully ME, Canny MJ, Rogiers SY (2016) The amino acid distribution in rachis xylem sap and phloem exudate of Vitis vinifera 'Cabernet Sauvignon' bunches. Plant Physiol Biochem 105:45-54.

Granier A (1987) Evaluation of transpiration in a Douglas-fir stand by means of sap flow measurements. Tree Physiol 3:309-320.

Hentschel R, Bittner S, Janott M, Biernath C, Holst J, Ferrio JP, Gessler A, Priesack E (2013)

595 Simulation of stand transpiration based on a xylem water flow model for individual trees. Agric For 596 Meteorol 182-183:31-42.

597 Herdel K, Schmidt P, Feil R, Mohr A, Schurr U (2001) Dynamics of concentrations and nutrient 598 fluxes in the xylem of Ricinus communis - Diurnal course, impact of nutrient availability and 599 nutrient uptake. Plant, Cell Environ 24:41-52.

600 Inselsbacher E, Näsholm T (2012) A novel method to measure the effect of temperature on diffusion 601 of plant-available nitrogen in soil. Plant Soil 354:251-257. 
Inselsbacher E, Öhlund J, Jämtgård S, Huss-Danell K, Näsholm T (2011) The potential of 603 microdialysis to monitor organic and inorganic nitrogen compounds in soil. Soil Biol Biochem

Jonard M, Fürst A, Verstraeten A, Thimonier A, Timmermann V, Potočić N, Waldner P, Benham S,

Hansen K, Merilä P, Ponette Q, Cruz AC de la, Roskams P, Nicolas M, Croisé L, Ingerslev M,

Matteucci G, Decinti B, Bascietto M, Rautio P (2015) Tree mineral nutrition is deteriorating in 608 Europe. Glob Chang Biol 21:418-430.

Julie A S (1999) Methods and issues in microdialysis calibration. Anal Chim Acta 379:337-358. http://www.sciencedirect.com/science/article/pii/S0003267098005984

Kho CM, Enche Ab Rahim SK, Ahmad ZA, Abdullah NS (2017) A Review on Microdialysis Calibration Methods: the Theory and Current Related Efforts. Mol Neurobiol 54:3506-3527.

Köstner B, Schupp R, Schulze ED, Rennenberg H (1998) Organic and inorganic sulfur transport in the xylem sap and the sulfur budget of Picea abies trees. Tree Physiol 18:1-9.

Lambers H, Albornoz F, Kotula L, Laliberté E, Ranathunge K, Teste FP, Zemunik G (2018) How

616 belowground interactions contribute to the coexistence of mycorrhizal and non-mycorrhizal species 617 in severely phosphorus-impoverished hyperdiverse ecosystems. Plant Soil 424:11-33.

618 Lambers H, Shane MW, Cramer MD, Pearse SJ, Veneklaas EJ (2006) Root structure and 619 functioning for efficient acquisition of phosphorus: Matching morphological and physiological 620 traits. Ann Bot 98:693-713.

621 Lang F, Krüger J, Amelung W, Willbold S, Frossard E, Bünemann EK, Bauhus J, Nitschke R, 622 Kandeler E, Marhan S, Schulz S, Bergkemper F, Schloter M, Luster J, Guggisberg F, Kaiser K, 623 Mikutta R, Guggenberger G, Polle A, Pena R, Prietzel J, Rodionov A, Talkner U, Meesenburg H, 624 von Wilpert K, Hölscher A, Dietrich HP, Chmara I (2017) Soil phosphorus supply controls P nutrition strategies of beech forest ecosystems in Central Europe. Biogeochemistry 136:5-29. 
Lang F, Bauhus J, Frossard E, George E, Kaiser K, Kaupenjohann M, Krüger J, Matzner E, Polle A,

Prietzel J, Rennenberg H, Wellbrock N (2016) Phosphorus in forest ecosystems: New insights from an ecosystem nutrition perspective. J Plant Nutr Soil Sci 179:129-135.

Lopushinsky W (1986) Seasonal and diurnal trends of heat pulse velocity in Douglas-fir and ponderosa pine. Can J For Res 16:814-821.

Martínez-Vilalta J, Garcia-Forner N (2017) Water potential regulation, stomatal behaviour and hydraulic transport under drought: deconstructing the iso/anisohydric concept. Plant Cell Environ 40:962-976.

Miró M, Frenzel W (2004) Implantable flow-through capillary-type microdialyzers for continuous in situ monitoring of environmentally relevant parameters. Anal Chem 76:5974-5981.

Miró M, Frenzel W (2005) The potential of microdialysis as an automatic sample-processing technique for environmental research. TrAC - Trends Anal Chem 24:324-333. in secondary xylem of seed plants. New Phytol 209:1553-1565.

Murphy J, Riley JP (1962) A modified single solution method for the determination of phosphate in natural waters. Anal Chim Acta 27:31-36.

Netzer F, Schmid C, Herschbach C, Rennenberg H (2017) Phosphorus-nutrition of European beech (Fagus sylvatica L.) during annual growth depends on tree age and P-availability in the soil. Environ Exp Bot 137:194-207.

Peuke AD, Rokitta M, Zimmermann U, Schreiber L, Haase A (2001) Simultaneous measurement of water flow velocity and solute transport in xylem and phloem of adult plants of Ricinus communis over a daily time course by nuclear magnetic resonance spectrometry. Plant, Cell Environ 24:491- 
Pretti L, Bazzu G, Serra PA, Nieddu G (2014) A novel method for the determination of ascorbic

651 acid and antioxidant capacity in Opuntia ficus indica using in vivo microdialysis. Food Chem 652 147:131-137. http://dx.doi.org/10.1016/j.foodchem.2013.09.120

653 R Development Core Team (2019) R: A language and environment for statistical computing. 654 https://www.r-project.org/

655 Regulski FJJ, Peterson JL (1981) Portable device for the extraction of xylem sap from trees. Plant 656 Dis 66:53-54.

657 Santi S, Locci G, Monte R, Pinton R, Varanini Z (2003) Induction of nitrate uptake in maize roots: 658 Expression of a putative high-affinity nitrate transporter and plasma membrane H+-ATPase 659 isoforms. J Exp Bot 54:1851-1864.

660 Schneider S, Gessler A, Weber P, von Sengenbusch D, Hanemann U, Rennenberg H (1996) Soluble $661 \mathrm{~N}$ compounds in trees exposed to high loads of $\mathrm{N}$ : a comparison of spruce (Picea abies) and beech 662 (Fagus sylvatica) grown under field conditions. New Phytol 134:103-114. 663 http://dx.doi.org/10.1111/j.1469-8137.1996.tb01150.x

664 Schupp R (1991) Untersuchungen zur Schwefelernährung der Fichte (Picea abies L.). 665 Wissenschafts-Verlag W Maraun, Frankfurt a M, Ger

666 Schurr U (1998) Xylem sap sampling - New approaches to an old topic. Trends Plant Sci 3:293667298.

668 Siebrecht S, Herdel K, Schurr U, Tischner R (2003) Nutrient translocation in the xylem of poplar669 Diurnal variations and spatial distribution along the shoot axis. Planta 217:783-793.

670 SPERRY JS, DONNELLY JR, TYREE MT (1988) A method for measuring hydraulic conductivity 671 and embolism in xylem. Plant Cell Environ 11:35-40.

672 Stenken JA (1999) Methods and issues in microdialysis calibration. Anal Chim Acta 379:337-358. 
673 Takagi SI, Nomoto K, Takemoto T (1984) Physiological Aspect of Mugineic Acid, A Possible

674 Phytosiderophore of Graminaceous Plants. J Plant Nutr 7:469-477.

675 Thomas DS, Eamus D (2002) Seasonal patterns of xylem sap pH, xylem abscisic acid 676 concentration, leaf water potential and stomatal conductance of six evergreen and deciduous 677 Australian savanna tree species. Aust J Bot 50:229-236.

678 Torto N, Mwatseteza J, Sawula G (2002) A study of microdialysis sampling of metal ions. Anal 679 Chim Acta 456:253-261.

680 Volkmann THM, Kühnhammer K, Herbstritt B, Gessler A, Weiler M (2016) A method for in situ 681 monitoring of the isotope composition of tree xylem water using laser spectroscopy. Plant Cell 682 Environ 39:2055-2063.

683 Warren CR (2018) Development of online microdialysis-mass spectrometry for continuous 684 minimally invasive measurement of soil solution dynamics. Soil Biol Biochem

685 Watt M, Evans JR (1999) Linking development and determinacy with organic acid efflux from 686 proteoid roots of white lupin grown with low phosphorus and ambient or elevated atmospheric CO2 687 concentration. Plant Physiol 120:705-716.

688 Weber P, Stoermer H, Geßler A, Schneider S, Von Sengbusch D, Hanemann U, Rennenberg H 689 (1998) Metabolic responses of Norway spruce (Picea abies) trees to long-term forest management 690 practices and acute (NH4)2SO4 fertilization: Transport of soluble non-protein nitrogen compounds 691 in xylem and phloem. New Phytol 140:461-475.

692 WRB (2015) World reference base for soil resources 2014, update 2015. International soil 693 classification system for naming soils and creating legends for soil maps. World soil Resour reports

694 Zeppel MJB, Murray BR, Barton C, Eamus D (2004) Seasonal responses of xylem sap velocity to 695 VPD and solar radiation during drought in a stand of native trees in temperate Australia. Funct Plant 696 Biol 31:461-470. 
697 Zhou SN, Oakes KD, Servos MR, Pawliszyn J (2009) Use of simultaneous dual-probe 698 microdialysis for the determination of pesticide residues in a jade plant (Crassula ovata). Analyst $699 \quad 134: 748-754$.

700 Zhou SN, Ouyang G, Pawliszyn J (2008) Comparison of microdialysis with solid-phase 701 microextraction for in vitro and in vivo studies. J Chromatogr A 1196-1197:46-56. 


\section{Figures}

705 Figure 1. Sketch of $\mathrm{MD}$ probe and its function, $\left(\mathrm{C}_{\mathrm{dial}}\right.$, concentration in the dialysate; $\mathrm{C}_{\mathrm{per}}$, 706 concentration in the perfusate; $\mathrm{C}_{\infty}$, concentration in the surrounding medium).

707 Figure 2 . The setup of the stirred solution test $\left(\mathrm{C}_{\text {dial }}\right.$, concentration in the dialysate; $\mathrm{C}_{\text {per }}$, 708 concentration in the perfusate; $\mathrm{C}_{\infty}$, concentration in the surrounding medium).

709 Figure 3. Setup of the in vivo laboratory measurement. $\left(\mathrm{C}_{\text {dial }}\right.$, concentration in the dialysate; $C_{p e r}$, concentration in the perfusate; $\mathrm{C}_{\infty}$, concentration in the surrounding medium). The flow through the stem segment was controlled by the pressure head difference "h". The specific sap flow velocity was calculated from the amount of effluent from the stem segment (weighed with a scale) and the stem segment cross section area.

Figure 4: Schematic figure of the orientation of MD probes and heat pulse sap flow sensor. 715 Drawings are not to scale.

716 Figure 5: Details of the installation procedure. A) flushing of the MD probe chamber with deionized 717 water. B) and C) insertion of the MD probe in the chamber. D) sealing of the MD probe with 718 silicone. E) fully installed probe.

719 Figure 6. Relation between pumping rate (PR) and relative recovery (RR) derived from the in vitro 720 test. The exponential relationship (2) with high $\mathrm{R}^{2}$ shows a good fit with the data. Sample size is 721 indicated by $\mathrm{n}$, in the graph. Boxplots show median, $25^{\text {th }}$ and $75^{\text {th }}$ percentile, whiskers indicate \pm $722 \quad 1.5$ IQR and point symbols show outliers beyond this range.

723 Figure 7 . The effect of xylem sap flow velocity $J_{x y l e m}$ on the relative recovery (RR). The linear 724 relationship fitted to the dataset has a small slope, considerable variability and therefore low $\mathrm{R}^{2}$. 725 Qpump was set to $10 \mu \mathrm{L} \cdot \mathrm{min}^{-1}$.

726 Figure 8: Results of the $24 \mathrm{~h}$ measurement campaign applying the MD probes in a mature (circle) and a young beech tree (triangle). A: xylem sap flow velocity; B: dialysate concentration; $\mathrm{C}: \mathrm{PO}_{4}{ }^{3-}$ 
concentration calculated with formula (3) and the RR calibration curve shown in Figure 7; D mass

flux $\left(\mathrm{PO}_{4}{ }^{3-}\right.$ concentration multiplied by xylem sap flow velocity). Each data point represents the mean of all 3 probes installed in each tree. Whiskers show the standard deviation.

731 Figure 9: Temperature in the tree xylem during field measurements extracted from the xylem sap

732 flow sensors (see method section for details) and air temperature from the logger next to the trees.

733 Figure 10: Test of the MD probes performance prior and after the $24 \mathrm{~h}$ field campaign. The prior 734 measurement of probe 2 was excluded due to failure.

\section{Tables}

736 Table 1. Number of in vivo experiments under various analyte and perfusate concentrations.

737 Table 2. Stem segment number and used classified xylem sap flow velocity combinations

738 Table 3: t-student test for zero slope and intercept of the $\mathrm{RR} \sim \mathrm{J}_{\mathrm{xylem}}$ relationship

739 Table 4: Results of the ANOVA testing the influence of using different stem segments on the 740 relationship between $\mathrm{RR} \sim J_{x y l e m}$.

741 Table 5. Effect of varying analyte and perfusate $\mathrm{NaH}_{2} \mathrm{PO}_{4}$ and $\mathrm{KCl}$ concentration on the RR. Values 742 shown indicate mean RR with the standard deviation of RR in brackets.

743 Table 6: Results of the ANOVA testing the importance of $\mathrm{PO}_{4}{ }^{3-}$ and $\mathrm{KCl}$ concentrations on the 744 measured RR. 

inlet and outlet

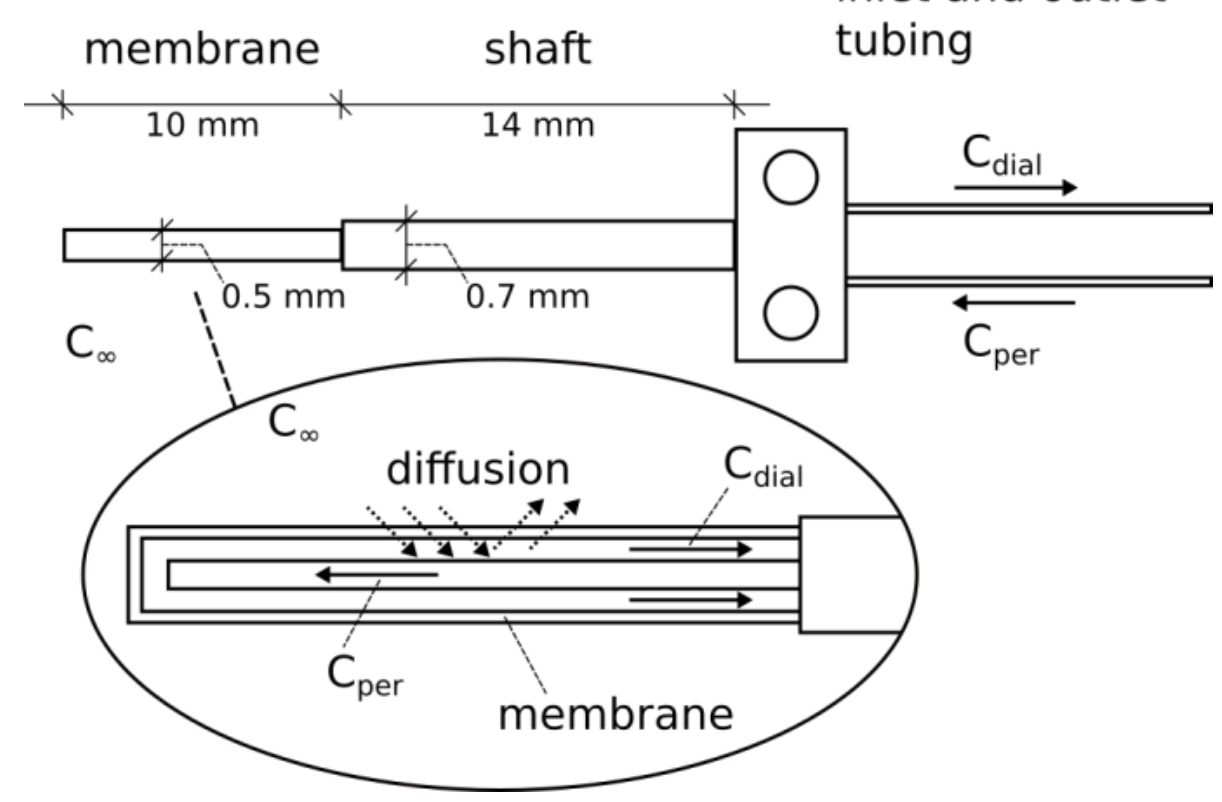

$748 \quad$ Figure 1

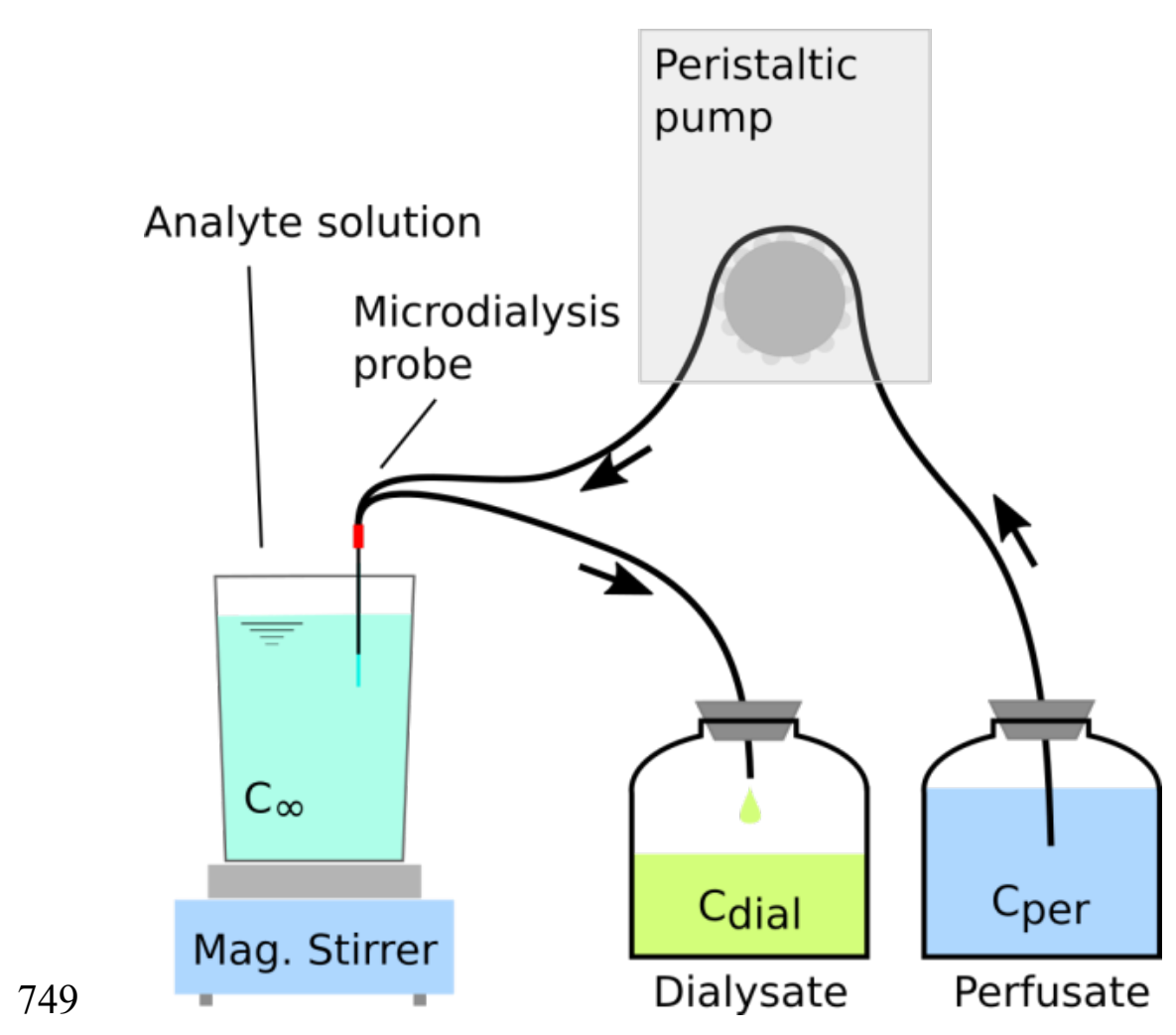

$750 \quad$ Figure 2 


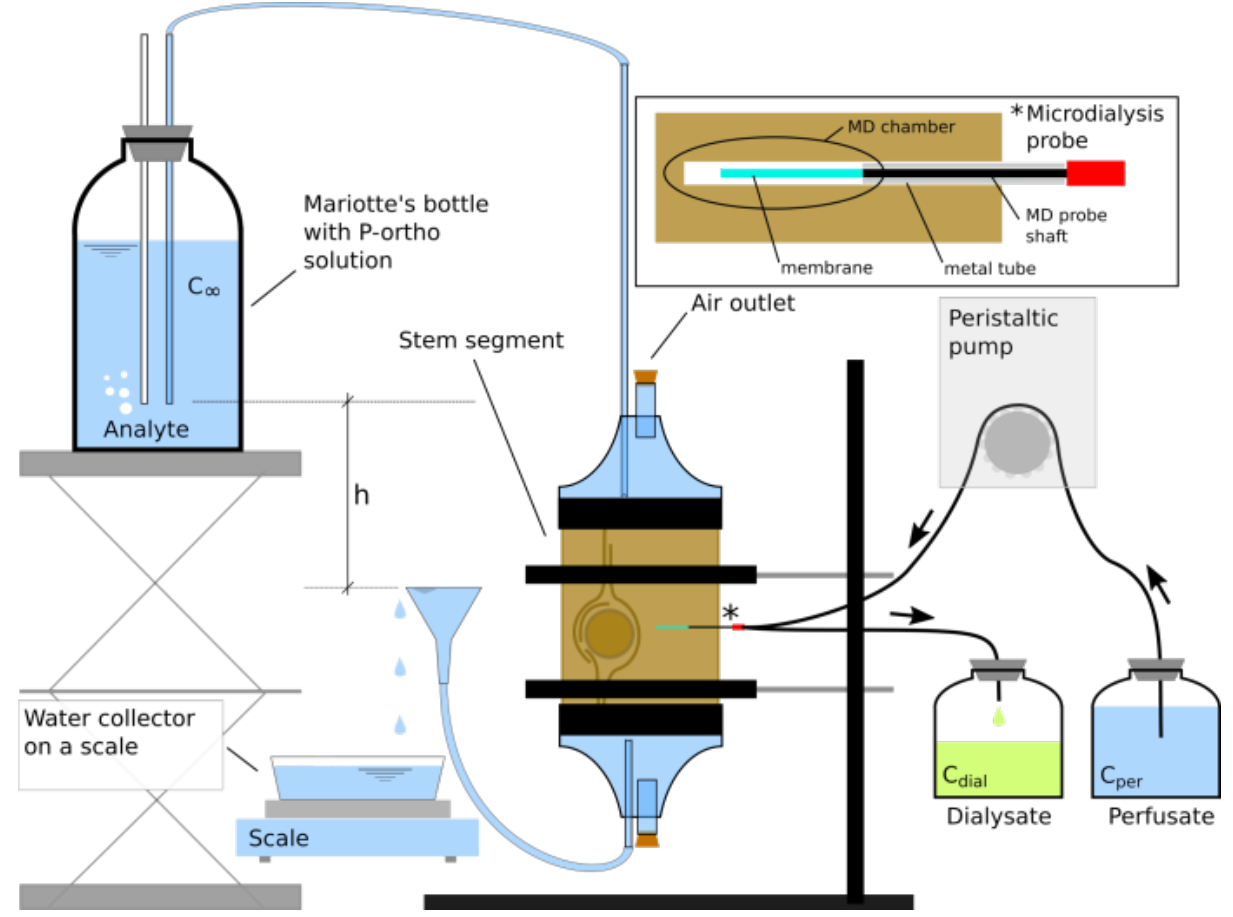

752 Figure 3

753
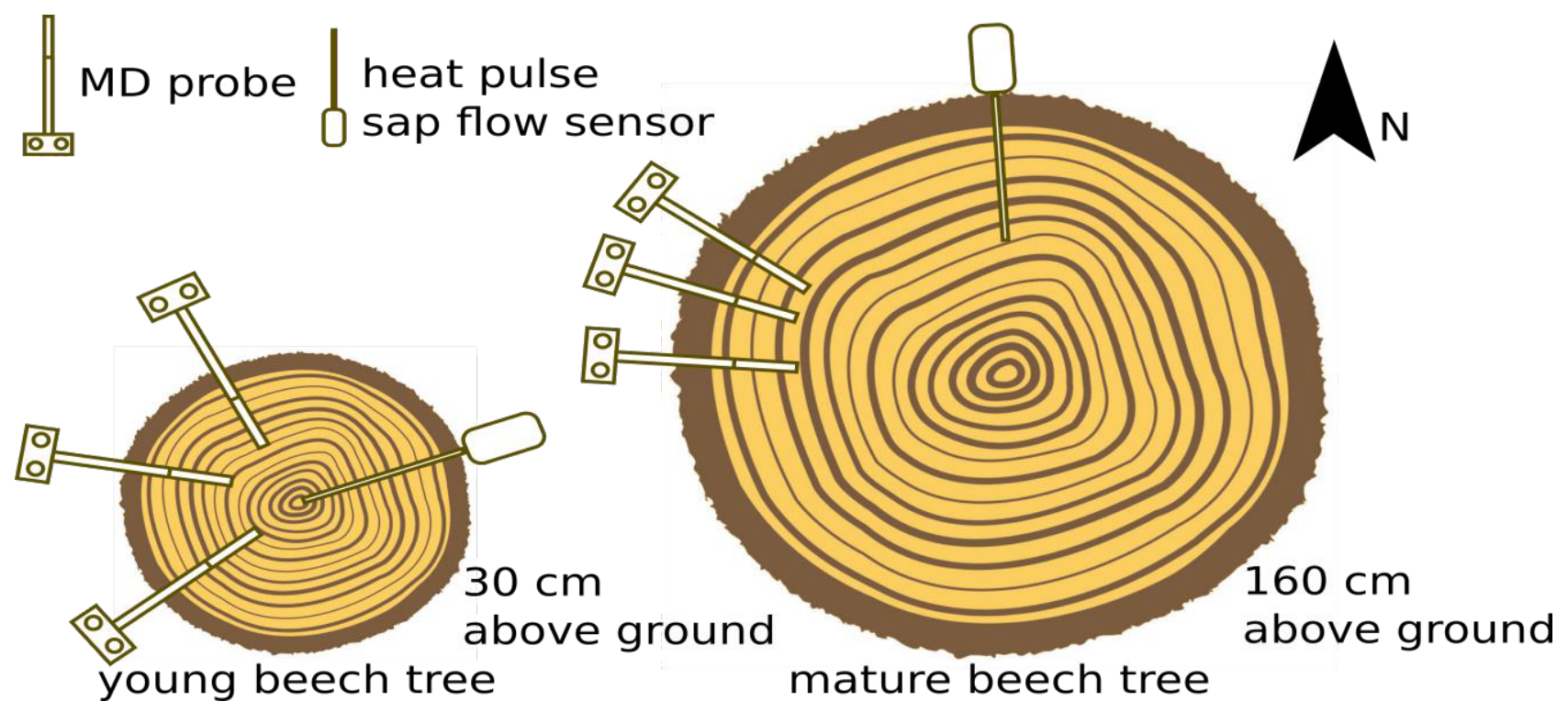

$755 \quad$ Figure 4 


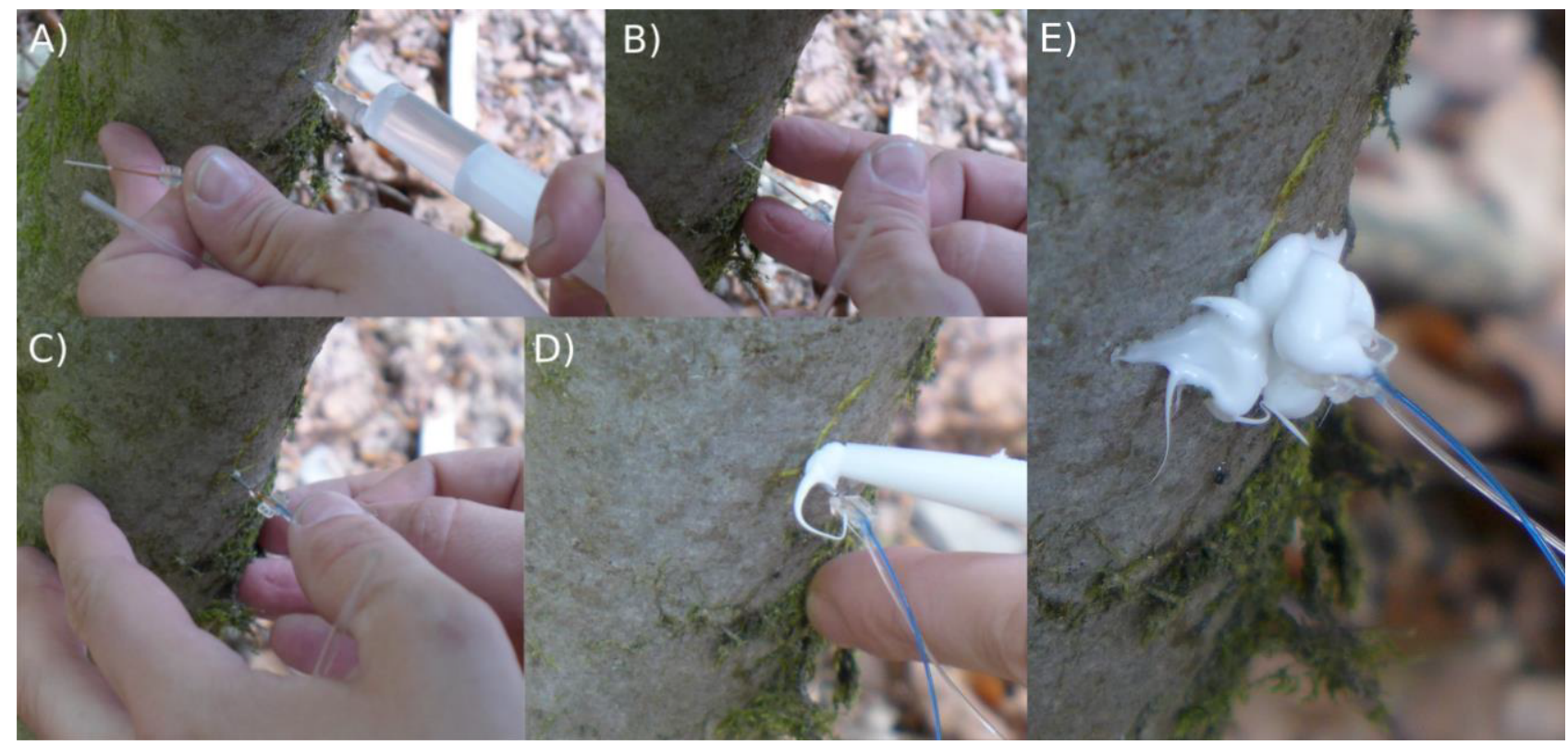

757 Figure 5

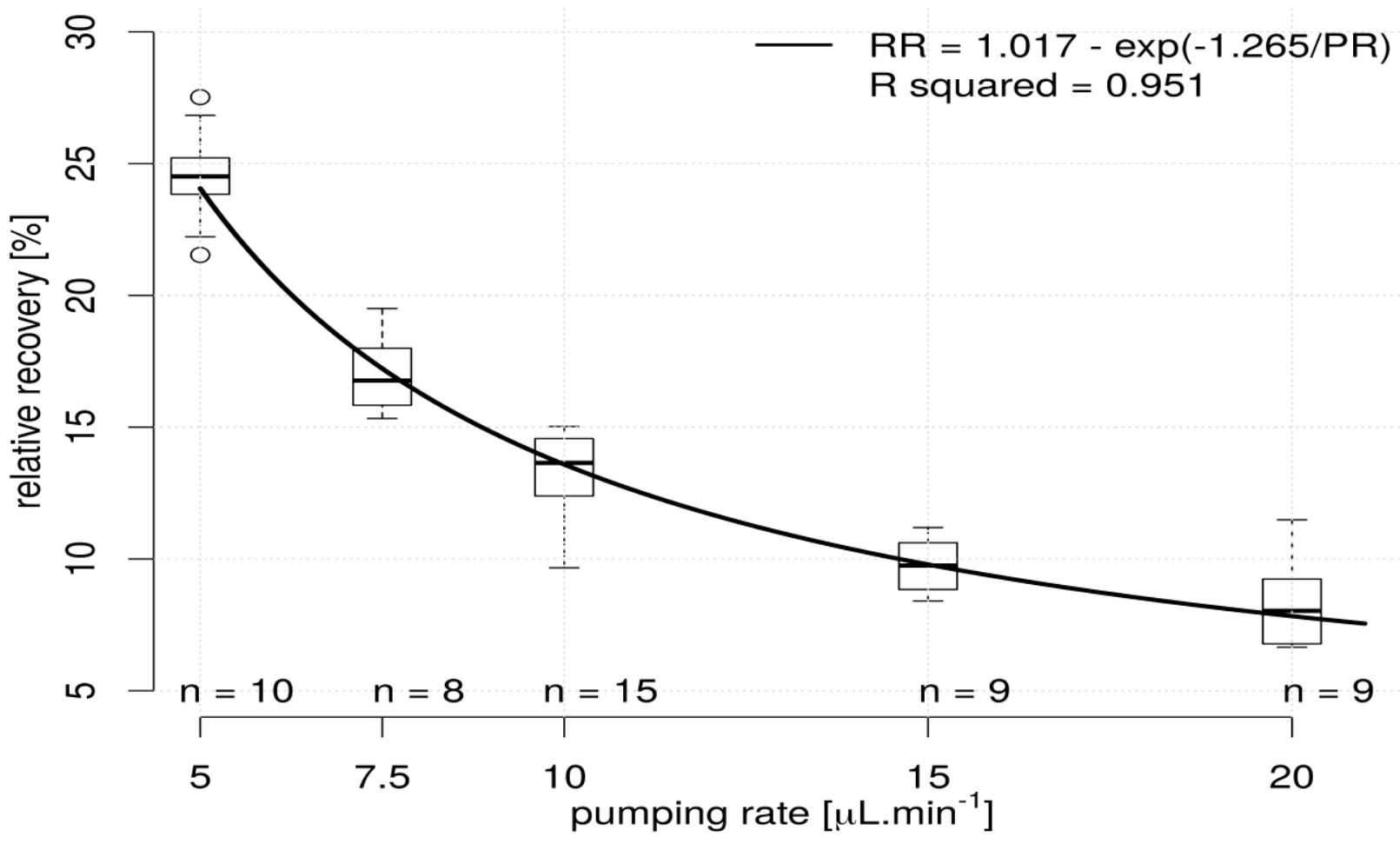

760 Figure 6 


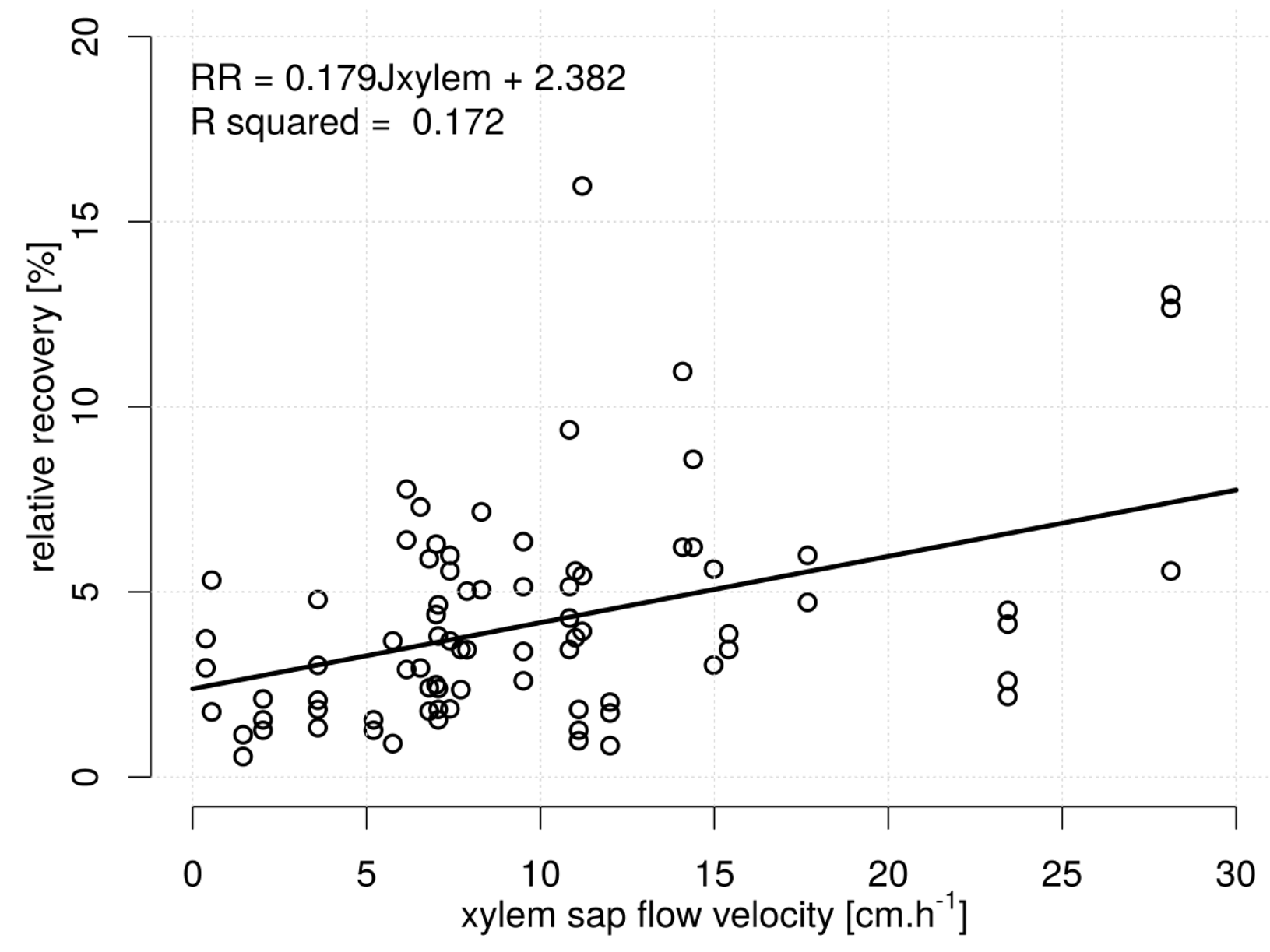

$762 \quad$ Figure 7 

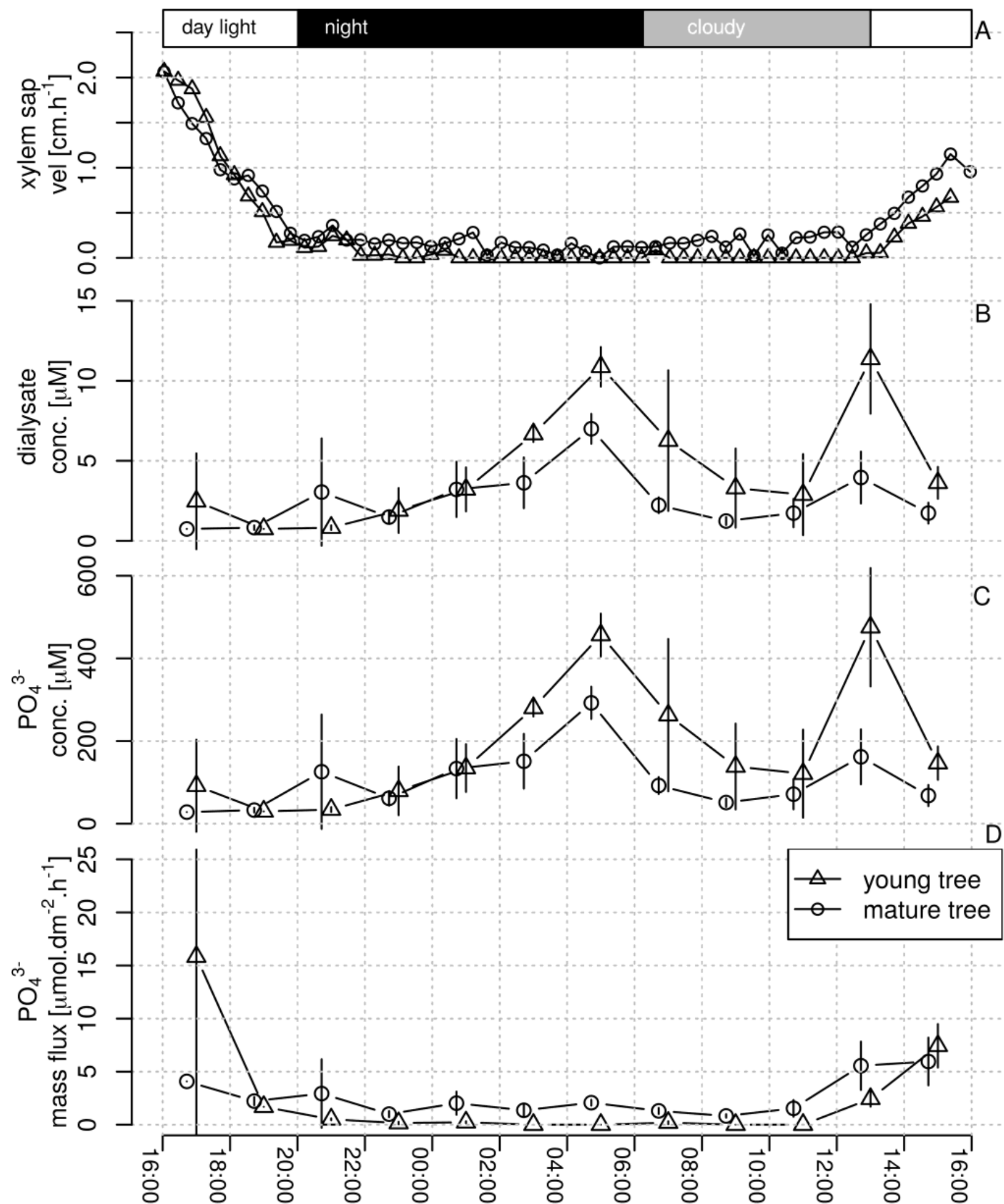

$764 \quad$ Figure 8 


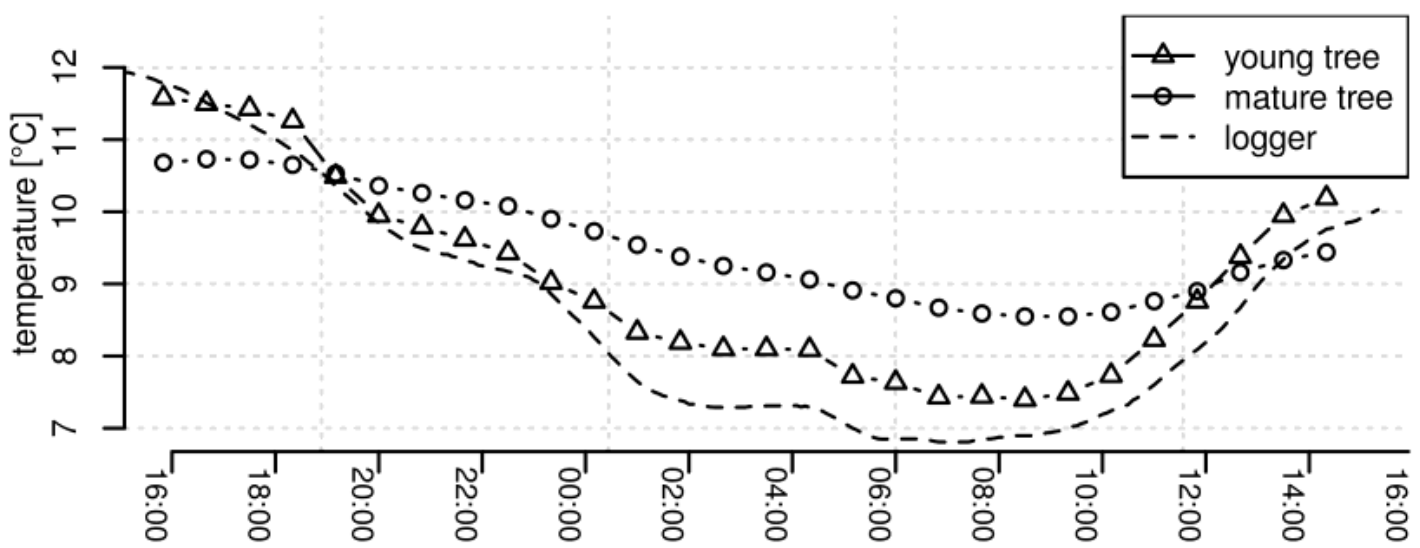

$766 \quad$ Figure 9

767

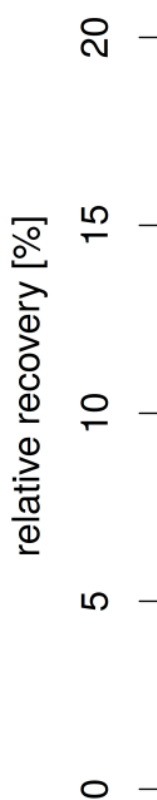

768

769

Figure 10

770
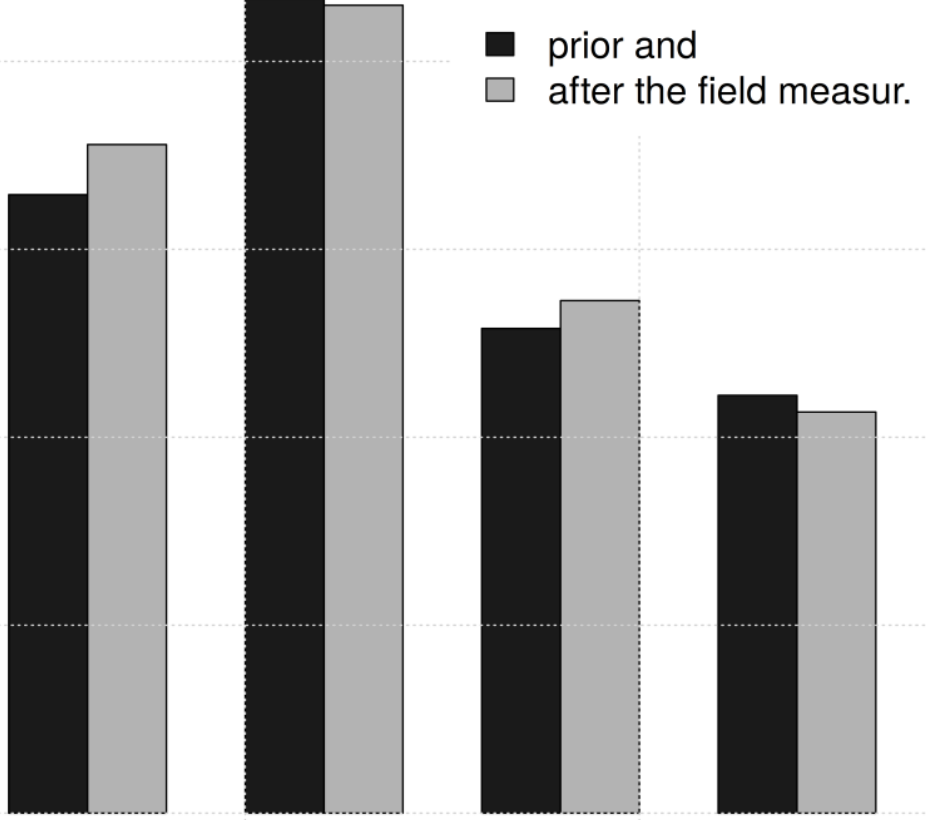

probe 4

probe 5 probe 6 probes used in mature tree
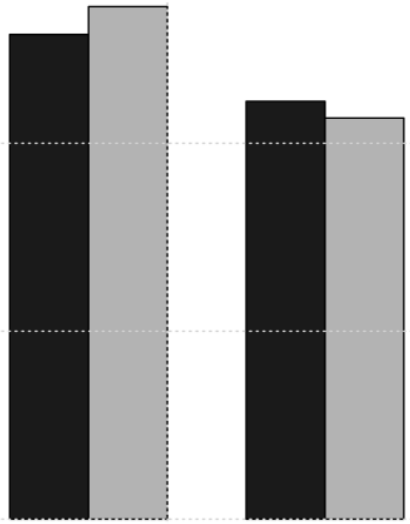

probe 1 probe 2 probe 3
probes used in young tree probes used in young tree 
Table 1 . Number of in vivo experiments under various analyte and perfusate concentrations.

\begin{tabular}{cccccc}
\hline & \multicolumn{3}{c}{ analyte $\mathrm{PO}_{4}{ }^{3-}$ conc. } & \multirow{2}{*}{ No. of } \\
\cline { 2 - 4 } & $5 \mathrm{M}$ & & \\
\cline { 2 - 5 } & 41.7 & 83.3 & 125 & measure. \\
\hline \multirow{2}{*}{ perfusate KCl con. $(\mathrm{mM})$} & 20 & 3 & $n / a$ & 3 & 6 \\
& 500 & 2 & 31 & 24 & 57 \\
No. of measure. & & 5 & 31 & 47 & 83 \\
\hline
\end{tabular}

Table 2. Stem segment number and used classified xylem sap flow velocity combinations

\begin{tabular}{|c|c|c|c|c|}
\hline & & \multicolumn{2}{|c|}{$\begin{array}{l}\text { Xylem sap flow } \\
\text { vel. }\left(\mathrm{cm} \mathrm{h}^{-1}\right)\end{array}$} & \multirow[t]{2}{*}{ No. of measurements } \\
\hline & & $<=6.93$ & $\begin{array}{c}<= \\
11.04\end{array}$ & \\
\hline \multirow{3}{*}{ Stem segment } & 1 & 6 & 4 & 10 \\
\hline & 2 & 6 & 6 & 12 \\
\hline & 3 & 4 & 4 & 8 \\
\hline No. of measure. & & 16 & 14 & 30 \\
\hline
\end{tabular}

Table 3: t-student test for zero slope and intercept of the RR Jxylem relationship

\begin{tabular}{|c|c|c|c|}
\hline Model & $\begin{array}{l}\text { Sample } \\
\text { size }\end{array}$ & $\begin{array}{l}\text { Intercept } \\
\text { value) }\end{array}$ & $\beta_{1} \quad(\mathrm{p}-$ \\
\hline $\operatorname{RR}\left(J_{\text {xylem }}\right)=\beta_{0}+\beta_{1} J_{\text {xylem }}$ & 83 & $2.38\left(3 e-5^{*}\right)$ & $0.18\left(5 \mathrm{e}-5^{*}\right)$ \\
\hline
\end{tabular}

Table 4: Results of the ANOVA testing the influence of using different stem segments on the relationship between $\mathrm{RR} \sim J_{x y l e m}$.

\begin{tabular}{lllll}
\hline & Sum of Sq. (T. III) & DF & $\begin{array}{l}\mathrm{F} \\
\text { value }\end{array}$ & $\mathrm{P}(>\mathrm{F})$ \\
\hline Intercept & 685.86 & 1 & 116.74 & $<0.0 \mathrm{e}-5$ \\
Used stem seg. & 31.8 & 2 & 2.7 & 0.08 \\
Classified $_{\text {xylem }}$ & 2 & 1 & 0.34 & 0.56 \\
Interaction & 26.6 & 2 & 2.27 & 0.12 \\
Residuals & 141 & 24 & & \\
\hline
\end{tabular}


Table 5. Effect of varying analyte and perfusate $\mathrm{NaH}_{2} \mathrm{PO}_{4}$ and $\mathrm{KCl}$ concentration on the $\mathrm{RR}$. Values shown indicate mean RR with the standard deviation of RR in brackets.

perfusate $\mathrm{KCl}$ con. $(\mathrm{mM})$

\begin{tabular}{cccc} 
& & \multicolumn{2}{c}{$\left(\mathrm{NaH}_{2} \mathrm{PO}_{4}{ }^{3-}=0 \mathrm{mM}\right)$} \\
\cline { 2 - 4 } & 500 & 20 \\
\hline $\begin{array}{c}\text { analyte } \\
\mathrm{NaH}_{2} \mathrm{PO}_{4}{ }^{3-} \\
\begin{array}{c}\text { con. }(\mathrm{mM}) \\
(\mathrm{KCl}=0 \mathrm{mM})\end{array}\end{array}$ & 125 & $4.39(1.9)$ & $3.36(2.2)$ \\
\hline
\end{tabular}

Table 6: Results of the ANOVA testing the importance of $\mathrm{PO}_{4}{ }^{3-}$ and $\mathrm{KCl}$ concentrations on the measured RR.

\begin{tabular}{|c|c|c|c|c|}
\hline & $\begin{array}{l}\text { Sum of Sq. (T. } \\
\text { III) }\end{array}$ & DF & $\mathrm{F}$ value & $\mathrm{P}(>\mathrm{F})$ \\
\hline Intercept & 604.56 & 1 & 16.4 & 0.003 \\
\hline $\mathrm{PO}_{4}{ }^{3-}$ conc. & 124.55 & 1 & 3.37 & 0.1 \\
\hline $\mathrm{aKCl}$ conc. & 17.11 & 1 & 0.46 & 0.51 \\
\hline Residuals & 332.55 & 9 & & \\
\hline
\end{tabular}

